\title{
Current approaches to treatments for schizophrenia spectrum disorders, part I: an overview and medical treatments
}

This article was published in the following Dove Press journal:

Neuropsychiatric Disease and Treatment

10 September 2013

Number of times this article has been viewed

\section{Wai Tong Chien}

\section{Annie LK Yip}

School of Nursing, Faculty of Health and Social Sciences, The Hong Kong Polytechnic University, Hung Hom, Kowloon, Hong Kong

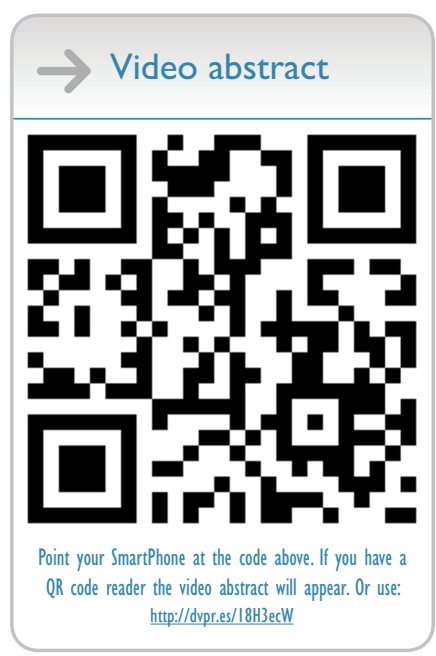

Correspondence: Wai Tong Chien School of Nursing, The Hong Kong Polytechnic University, Hung Hom, Kowloon, Hong Kong

Tel +85227665648

Fax +852 2334 II 24

Email wai.tong.chien@polyu.edu.hk
Abstract: During the last three decades, an increasing understanding of the etiology, psychopathology, and clinical manifestations of schizophrenia spectrum disorders, in addition to the introduction of second-generation antipsychotics, has optimized the potential for recovery from the illness. Continued development of various models of psychosocial intervention promotes the goal of schizophrenia treatment from one of symptom control and social adaptation to an optimal restoration of functioning and/or recovery. However, it is still questionable whether these new treatment approaches can address the patients' needs for treatment and services and contribute to better patient outcomes. This article provides an overview of different treatment approaches currently used in schizophrenia spectrum disorders to address complex health problems and a wide range of abnormalities and impairments resulting from the illness. There are different treatment strategies and targets for patients at different stages of the illness, ranging from prophylactic antipsychotics and cognitive-behavioral therapy in the premorbid stage to various psychosocial interventions in addition to antipsychotics for relapse prevention and rehabilitation in the later stages of the illness. The use of antipsychotics alone as the main treatment modality may be limited not only in being unable to tackle the frequently occurring negative symptoms and cognitive impairments but also in producing a wide variety of adverse effects to the body or organ functioning. Because of varied pharmacokinetics and treatment responsiveness across agents, the medication regimen should be determined on an individual basis to ensure an optimal effect in its long-term use. This review also highlights that the recent practice guidelines and standards have recommended that a combination of treatment modalities be adopted to meet the complex health needs of people with schizophrenia spectrum disorders. In view of the heterogeneity of the risk factors and the illness progression of individual patients, the use of multifaceted illness management programs consisting of different combinations of physical, psychological, and social interventions might be efficient and effective in improving recovery.

Keywords: schizophrenia, schizophrenia spectrum disorders, treatment, psychosocial intervention, pharmacology, antipsychotics

\section{Introduction}

Schizophrenia and its spectrum disorders (all falling under the term "schizophrenia" in this article) are chronic remitting and disruptive disorders associated with significant abnormalities and the progressive deterioration of a wide variety of cognitive, psychosocial, vocational, and behavioral functioning. The fourth edition of the Diagnostic and Statistical Manual of Mental Disorders (DSM-IV) defines schizophrenia as a syndrome characterized by long duration, high relapse rate $(>70 \%)$, bizarre delusions and behaviors, negative symptoms, and sometimes a few mood problems. ${ }^{1}$ The onset of symptoms typically occurs in adolescence and young adulthood, with a worldwide 
estimate of its lifetime prevalence and incidence of 1.4-4.6 and $0.16-0.42$ per 1,000 persons annually, respectively. ${ }^{2,3}$ A recent systematic review indicated that patients diagnosed with this disorder have a shorter lifespan than the average general population and are particularly at risk for suicide, increased physical risk (eg, limited exercise, poor diet, and obesity), and reduced access to medical treatment and healthcare services. ${ }^{4}$ In addition, $5 \%-8 \%$ of healthy people indicate an attenuated form of schizoid personality and schizophrenia-like symptoms, such as paranoid delusional thinking and auditory hallucination. ${ }^{5}$

Because of the complex health problems and wide range of abnormalities and impairments concerning schizophrenia, comprehensive and multimodal treatment approaches are considered and tested in different combinations, with the goal of reducing patients' illness episodes and symptoms, as well as improving their functioning and quality of life in the longer term. Antipsychotic medications have been recommended consistently and continuously as the mainstream and standard treatment for nearly all patients with schizophrenia, to provide them with a safe and therapeutic environment and effective symptom control since the introduction of chlorpromazine (the first antipsychotic) in the 1960s. In the last three to four decades, physical treatments such as electroconvulsive therapy (ECT; in the 1930s) and different approaches to psychosocial interventions such as psychoanalysis (in the 1950s), family therapy (in the 1960s), psychoeducation (in the 1980s), cognitive-behavioral therapy (in the 1990s), and cognitive remediation (in the 2000s) have been introduced successively, ${ }^{7-14}$ and their comparative or combined efficacies for schizophrenia treatment have been increasingly evaluated in various clinical trials. ${ }^{8,10,12,13}$ Recent systematic reviews and practice guidelines have recommended that as an adjunct to psychopharmacological treatment, psychosocial interventions designed to support both people with schizophrenia and their families should also be used to improve their rehabilitation, reintegration into the community, and recovery from the illness. ${ }^{6,15}$ Different modalities and combinations of psychosocial programs are recommended to address the complex individualized needs of these patients for multimodal care, particularly regarding relapse prevention, management of negative symptoms and cognitive dysfunction, and medication adherence. ${ }^{14,16}$ Despite increased recognition and demands for an individualized treatment plan and the integration of different intervention approaches to optimize patient outcomes, current psychiatric treatments and services still involve practicing the same set of treatment approaches for each patient group in the course of illness. More clinical trials are recommended to examine the active ingredients of unimodal or integrated psychosocial interventions for schizophrenia that can be effective in enhancing recovery and other patient outcomes. There has also been increasing attention and demand for cost-effectiveness analyses of these interventions.

To gain a more in-depth and focused understanding of the effects and benefits of recent approaches to treatments for schizophrenia, we performed a comparative review, summarized here, of the efficacy, safety, and tolerability of the current pharmacological and other medical treatments for these patients. In another article, we also performed a comparative review of the efficacy of approaches to psychosocial interventions for schizophrenia and a critical discussion about patient-focused perspectives of acceptance, benefits, and satisfaction in psychiatric care. Recommendations for best practices for continuity of schizophrenia care are also made. This article also provides an overview of the approaches to treatments across different stages of schizophrenia and the future direction of treatments for this illness.

\section{Review of current approaches to medical treatments for schizophrenia}

During the last two decades, the mainstream of medical treatment for schizophrenia has remained the use of antipsychotics and/or other psychotropic medications. With increasing initiatives and evidence of the effectiveness of psychosocial interventions for schizophrenia, the highly structured or manualized (eg, cognitive-behavioral and psychoeducation programs) and a few integrated programs (eg, the Schizophrenia Patient Outcomes Research Team Programs and the Recovery After an Initial Schizophrenia Episode Early Treatment Program in the United States), ${ }^{17,18}$ used as an adjunct to antipsychotics, have indicated positive patient outcomes. On the basis of several large-scale randomized controlled trials, single and multiple types of antipsychotics, or polypharmacy in combination with other psychotropic drugs, are considered useful in schizophrenia treatment. The introduction of second-generation antipsychotics has further improved the desired effects of these medications for schizophrenia care and, more important, reduced their undesirable effects such as extrapyramidal adverse effects, mortality, and metabolic disorder. Before exploring the recent changes or improvements needed in schizophrenia treatment and rehabilitation, it is important to review and understand the current knowledge about pharmacological and other medical treatments for schizophrenia sufferers. 


\section{Pharmacological treatment}

First- and second-generation antipsychotics

More than 70 antipsychotics have been introduced. They are mainly categorized into first- and second-generation agents and share a similar pharmacological mechanism in blocking the dopamine D-2 receptors. ${ }^{19}$ Their blocking mechanisms or actions are linked to their efficacy against positive and disorganization symptoms of schizophrenia. ${ }^{11-13}$

The first-generation antipsychotics (FGAs), or typical antipsychotics (eg, chlorpromazine, fluphenazine, and haloperidol, included in the World Health Organization's list of Essential Medications in 2009), ${ }^{20}$ were first introduced for the treatment of schizophrenia in the 1950s. The second-generation (atypical) antipsychotics (eg, clozapine, olanzapine, and risperidone) introduced in the last three decades were believed to be more efficacious and tolerable than the FGAs, and a few have progressively replaced the older FGAs to become the first-line prescription or the standard of care. To capture the research evidence or drug trials on antipsychotics, full-text articles published in English between 1966 and 2010 were searched for in CINAHL, MEDLINE, EMBASE, The Cochrane Library, Cochrane Schizophrenia Group's Register, Biological Abstracts, Sociological Abstracts, Sociofile, and PsycLIT. Participants included people with schizophrenia, schizophrenia-like psychoses such as schizophreniform and schizoaffective disorders, and psychotic disorders such as delusional disorder, nonaffective psychosis, or dual diagnosis. The main outcomes identified from the reviewed articles mainly involved mental state, global functioning, and adverse events.

Thirteen systematic reviews on the efficacy of FGAs using a randomized controlled trial design were found (Table 1). With similar intended outcomes, several outcome measurement tools were commonly used, including the Clinical Global Impression, Global Assessment Scale, and Global Assessment of Functioning scale for patients' global functioning; the Brief Psychiatric Rating Scale, Positive and Negative Syndrome Scale, Scale for the Assessment of Negative Symptoms, and Scale for the Assessment of Positive Symptoms for their mental state or symptom severity; and the Involuntary Movement Scale, Extrapyramidal Symptom Rating Scale, Extrapyramidal Rating Scale, and Simpson and Angus Scale for the adverse effects of medication used. Most of the clinical trials $(>70 \%)$ evaluated the medication effects over a short period of time (eg, up to 12 weeks), whereas a few $(<10 \%)$ involved a long-term follow-up (eg, $>1$ year).
The first FGA invented - chlorpromazine, has become the well-established and benchmark treatment for people with schizophrenia to facilitate their deinstitutionalization ${ }^{21}$ and has been used for more than 40 years. Nevertheless, the reviewed literature showed that the incidence and average dose of chlorpromazine prescribed to people with schizophrenia has been decreasing. ${ }^{22}$ Other commonly used FGAs such as trifluoperazine, thioridazine, sulpiride, pimozide, perphenazine, and fluphenazine were tested and confirmed to have similar and satisfactory efficacy in symptom reduction - mainly for positive symptoms (eg, delusions and hallucinations). ${ }^{23-28}$ However, there was limited evidence to support their efficacy at lower doses or in short-term treatment. ${ }^{28-31}$ Major adverse events induced by FGAs generally include sedation, movement disorders, endocrine disturbance, and metabolic and electrocardiogram changes. ${ }^{24,25,28,32}$

Most of all, FGAs are a relatively low-cost treatment and commonly used medication; however, there is little evidence to support their efficacy in reducing negative symptoms (eg, anhedonia, loss of volition, and social withdrawal) and cognitive functioning, which may contribute much to the functional disability of people with schizophrenia. ${ }^{26,29,33}$ It is generally concluded that there is similar satisfactory clinical efficacy in terms of mental state and global functioning across the FGAs and second-generation antipsychotics. ${ }^{34-37}$ However, a few trials indicate the superiority of individual second-generation agents over the FGAs in specific illness condition or patient outcomes..$^{29,33,37,38}$ In two meta-analyses of placebo-controlled trials,${ }^{39,40}$ haloperidol was reported to be less effective in reducing symptoms and/or relapse than certain second-generation agents (eg, clozapine and olanzapine).

Second-generation (or atypical) antipsychotics were believed to have good antipsychotic properties and minimal adverse effects compared with those noted with the use of FGAs. Some of them have been shown to be more efficacious and less problematic in terms of sedative and neurological effects than FGAs. ${ }^{41,42}$ Using the same databases and a similar procedure as the literature search on FGAs presented earlier, 12 systematic reviews (between 1966 and 2010) have been conducted to compare the effects among secondgeneration antipsychotics and the effects between these second-generation agents and FGAs or a placebo (Table 2). In addition to the main patient outcomes used (ie, mental state, global functioning, and relapse), several other psychosocial outcomes were usually compared across studies, including level of depression, acceptability of treatment (eg, dropout 


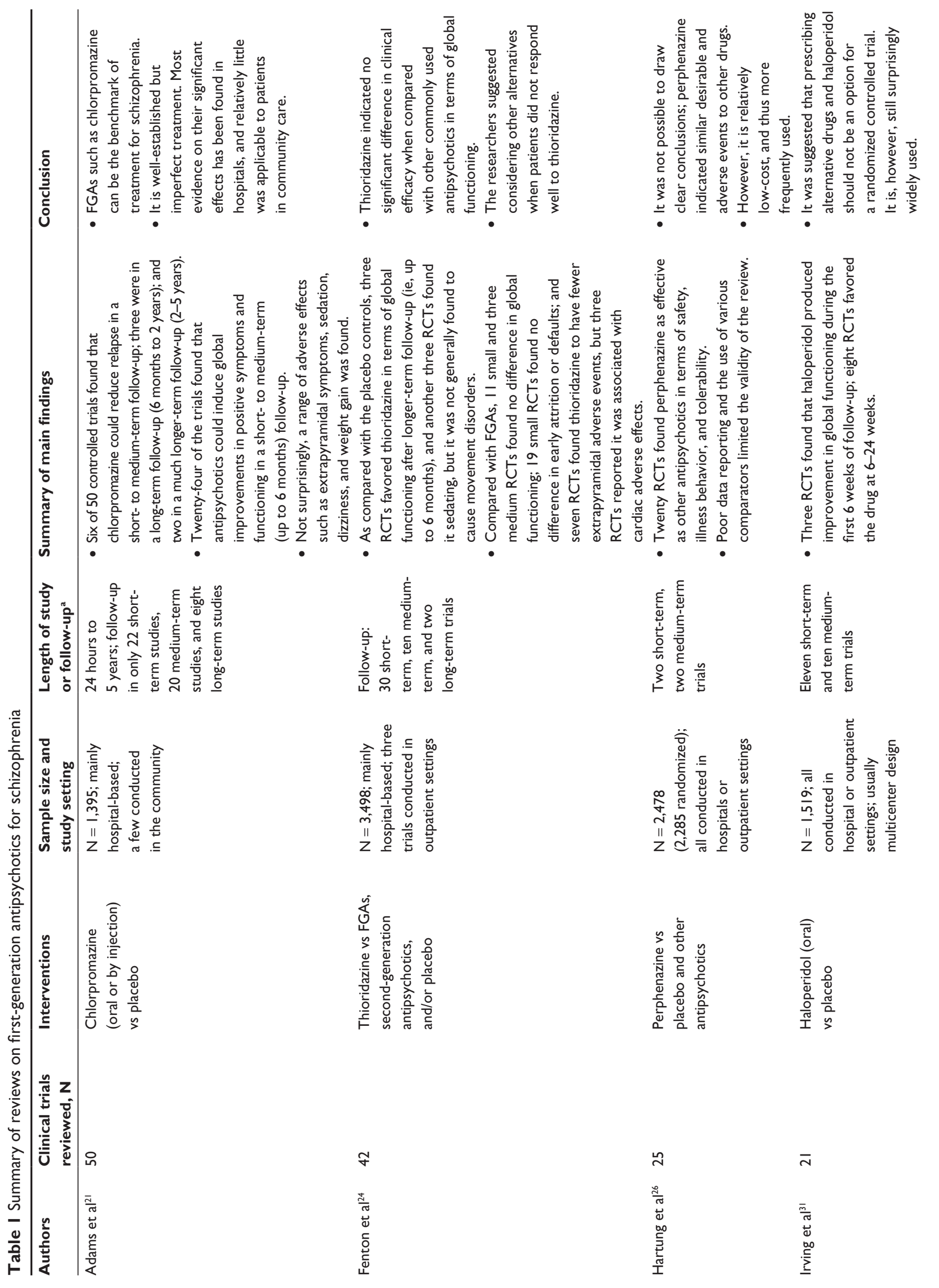



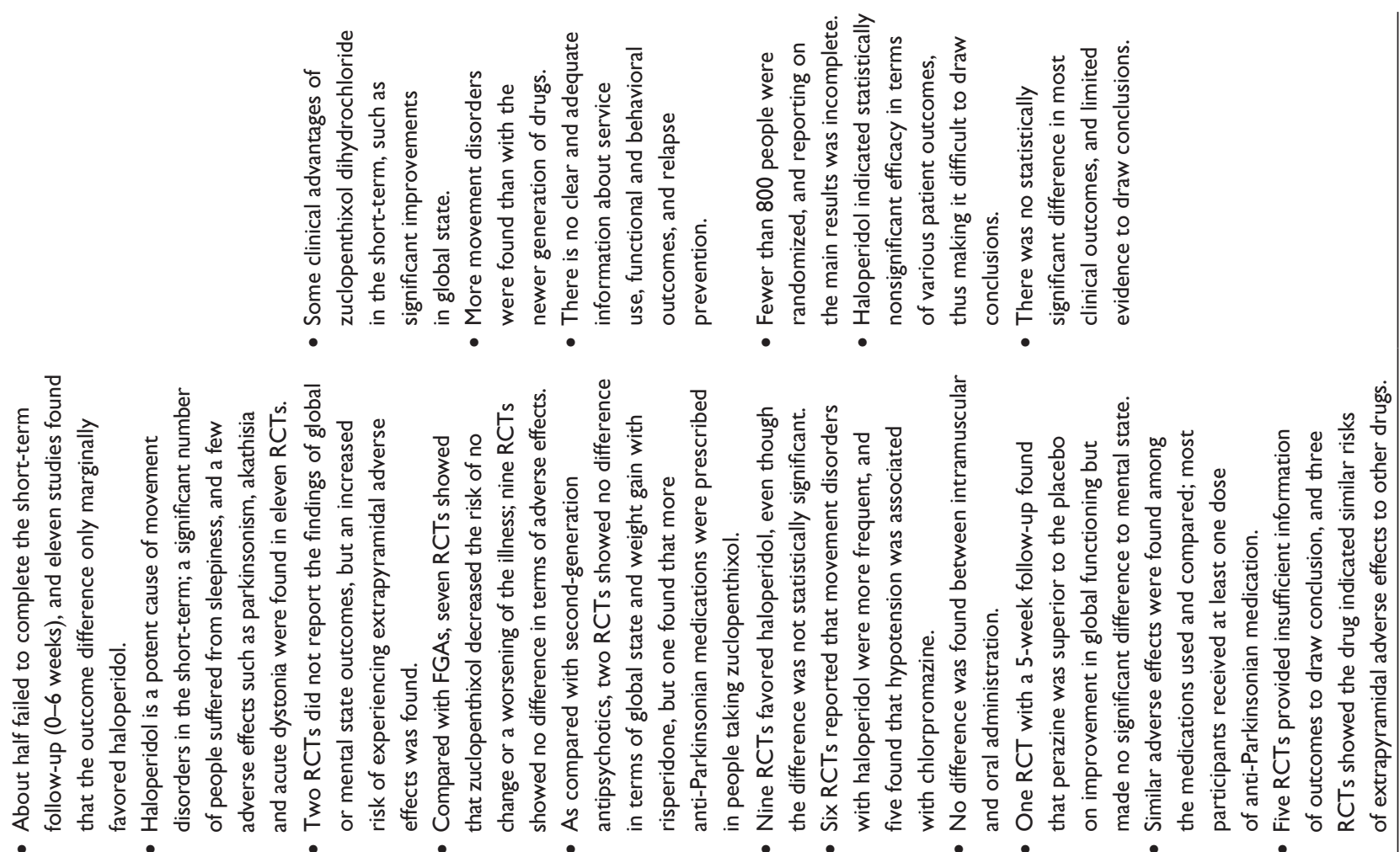

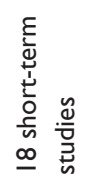
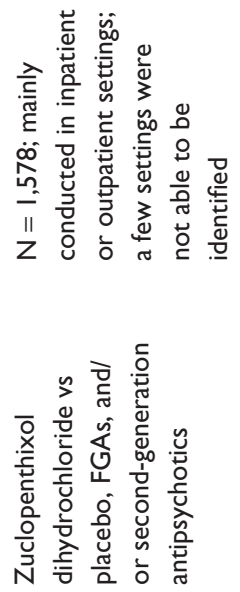

$\underline{\infty}$

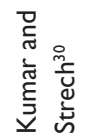

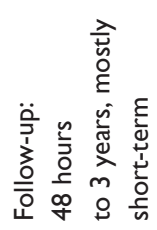

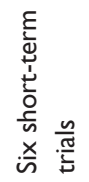
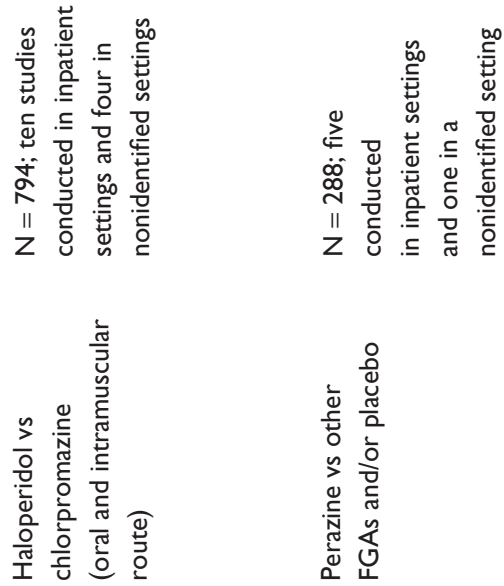


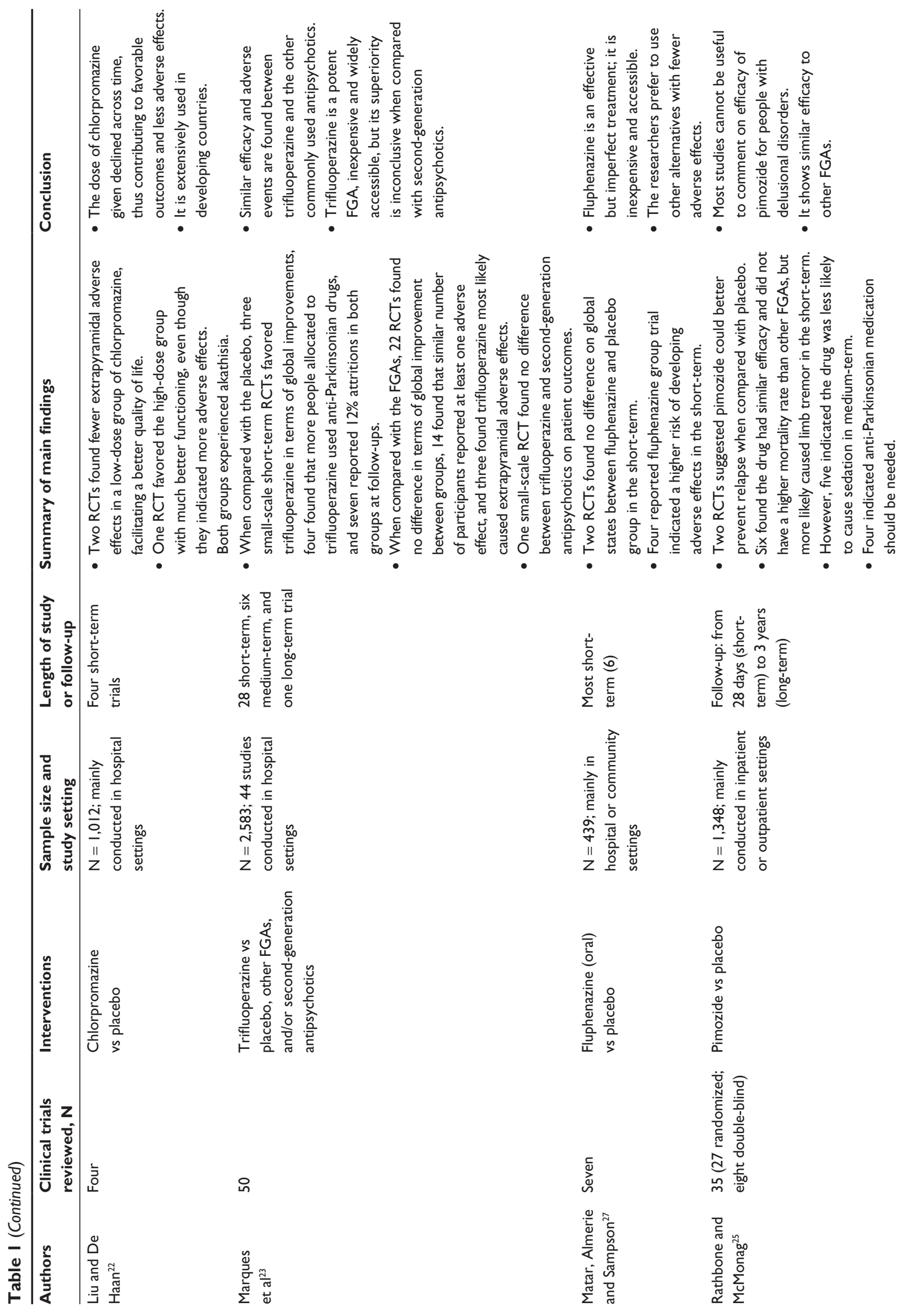



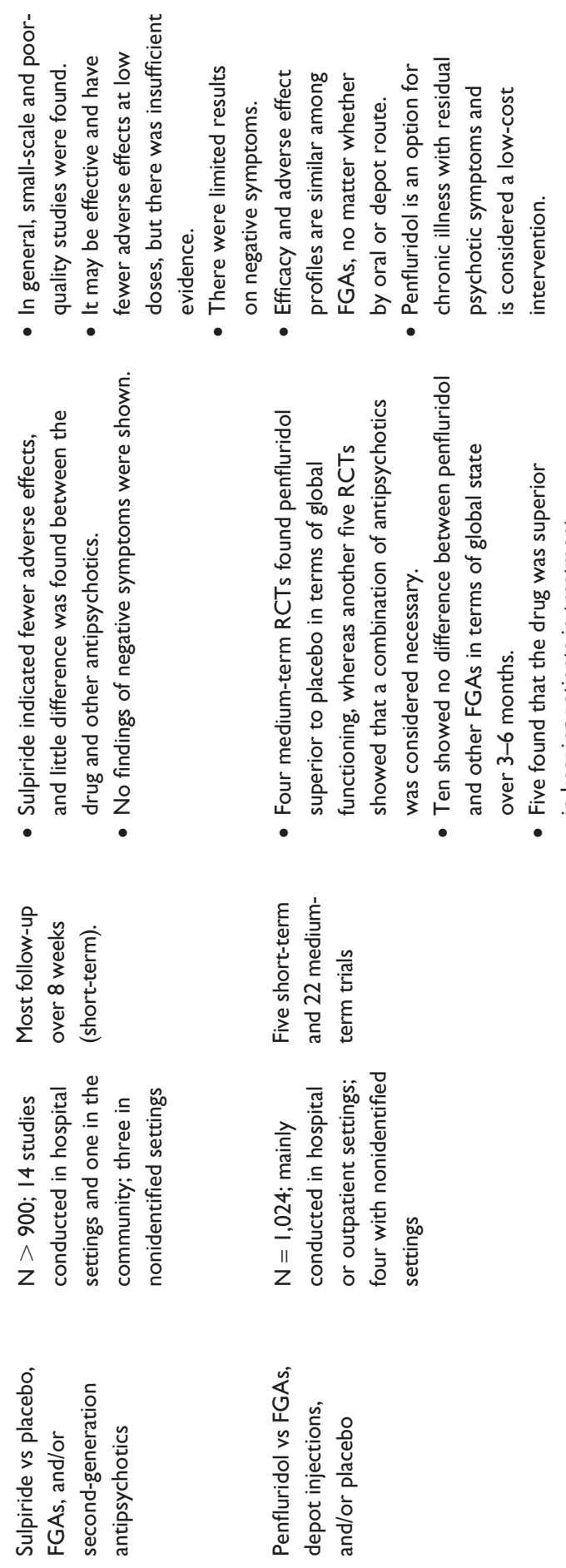

$\underline{\infty}$

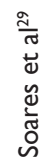

rate and patient dissatisfaction), inability to work, family burden, and social and cognitive functioning. Therefore, there are a wider variety of outcome measurements than used in previous studies, such as depression (eg, the Calgary Depression Scale, the Hamilton Rating Scale for Depression, or the Montgomery Asberg Depression Rating Scale), quality of life (eg, the Quality of Life Scale, the Schizophrenia Quality of Life Scale, the Subjective Well-being on Neuroleptics [Antipsychotics] Scale, or the Personal and Social Performance Scale), and patient satisfaction (eg, the Nurses Observational Scale Inpatients Evaluation) measures. Similar to those receiving FGAs, most of the clinical trials evaluated the short-term effects (up to 12 weeks) of the second-generation antipsychotics, even though a few longterm evaluations appear promising. ${ }^{39,40}$

A few systematic reviews also indicated that the controlled trials of second-generation antipsychotics have mainly tested only a few kinds, including risperidone, olanzapine, quetiapine, loxapine, sertindole, aripiprazole, and amisulpride, and mostly compared them with placebo controls. ${ }^{43-50}$ The reviews concluded that second-generation antipsychotics had similar effects to FGAs in terms of reduction of positive symptoms. The treatment efficacy of both FGAs and secondgeneration antipsychotics varies in terms of stages of the illness, with first-episode schizophrenia responding faster and better than at later illness stages. ${ }^{35,41,51}$ Nevertheless, most of the second-generation antipsychotics had comparatively fewer and lower levels of adverse effects such as movement disorders and cardiac and sedative problems than FGAs. Clozapine, the first second-generation antipsychotic, has been found to be particularly effective in treating refractory patients and reducing suicidality. ${ }^{36,41} \mathrm{~A}$ recent meta-analysis comparing nine second-generation antipsychotics with the FGAs (eg, chlorpromazine, fluphenazine and haloperidol) for overall efficacy concluded that four second-generation antipsychotics (namely, amisulpride, clozapine, olanzapine, and risperidone) were better than the FGAs, with small to medium effect sizes (ie, $0.13-0.52$ ). ${ }^{37}$ The four secondgeneration antipsychotics have been shown to induce fewer extrapyramidal adverse effects than the low-potency FGAs. Although olanzapine can induce more weight gain and production of prolactin, it is shown to exert a persistent treatment effect over other second-generation antipsychotics in chronic schizophrenia. ${ }^{37,52}$

A recent Cochrane's systematic review was published on nine randomized, placebo-controlled trials of aripiprazole, which is one of the newer second-generation antipsychotics. Its main results indicated that aripiprazole can significantly 


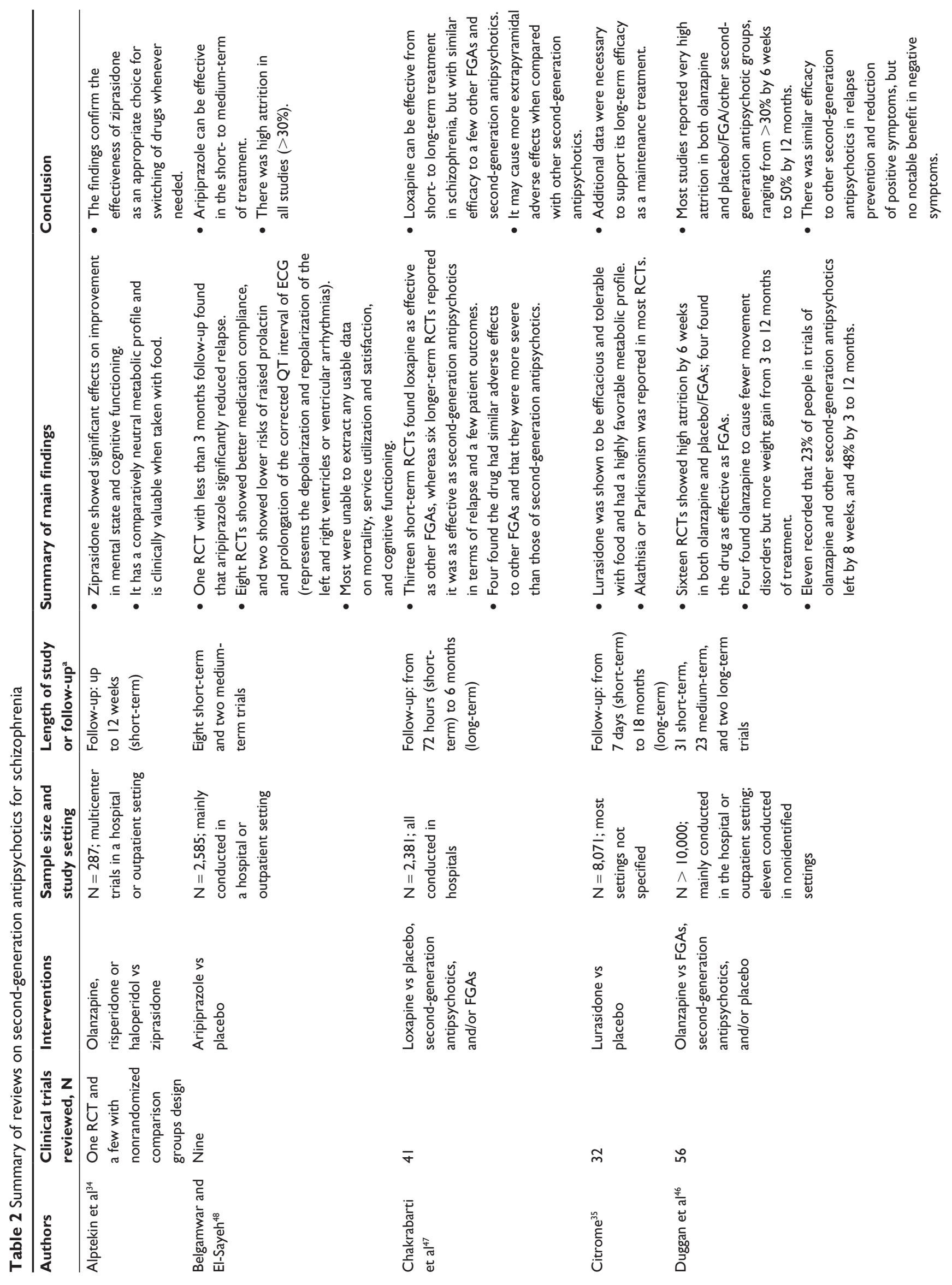




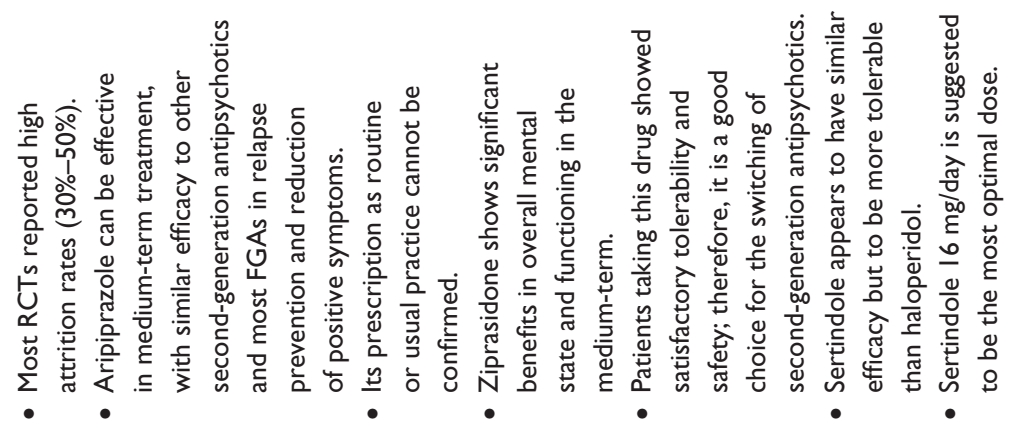
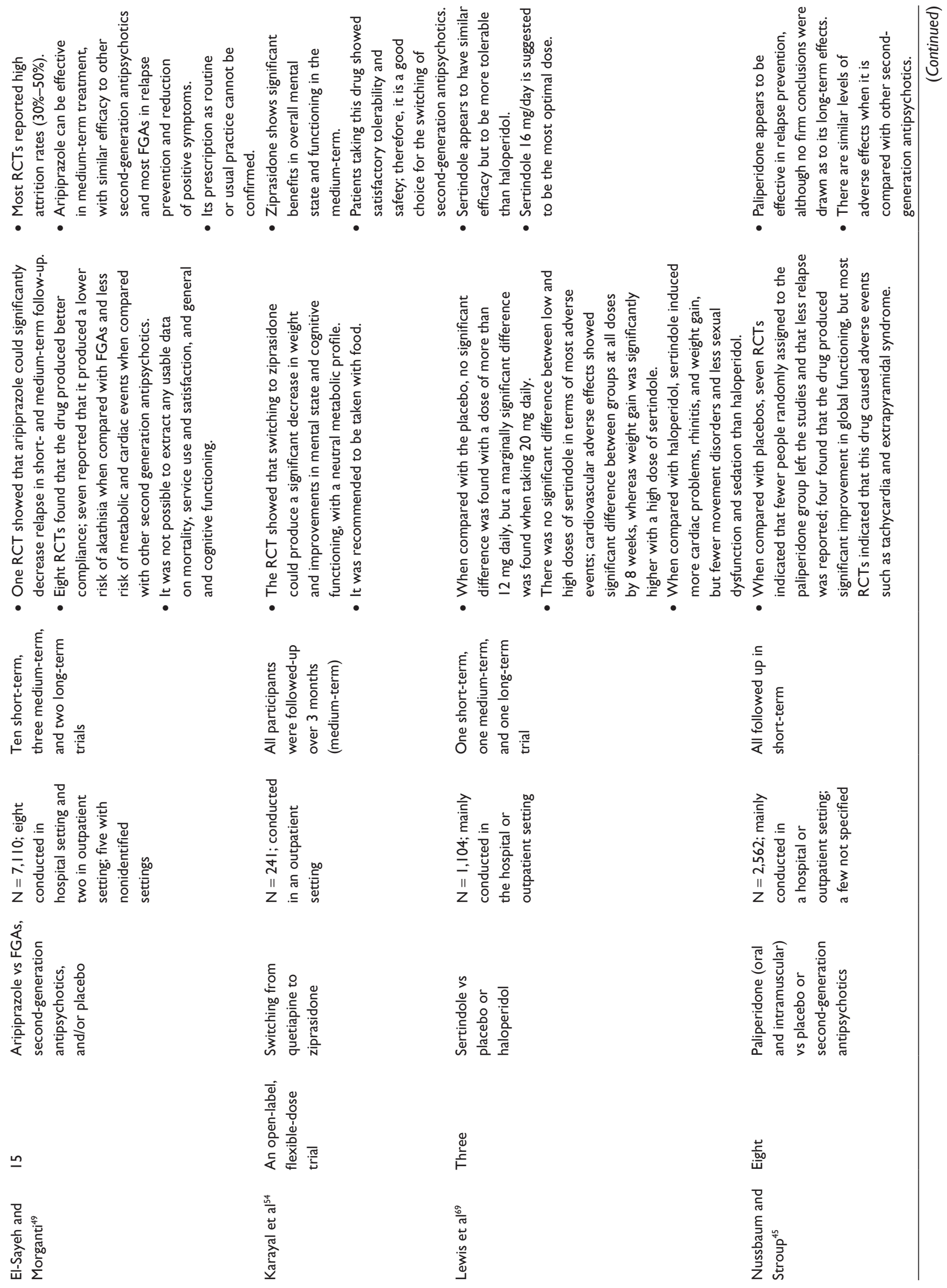

$\stackrel{\Xi}{\stackrel{\Xi}{\rightleftarrows}}$

$\underset{\mathrm{W}}{\mathrm{L}}$

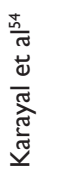

$\frac{0}{4}$
$\frac{0}{0}$
$\frac{0}{3}$
$\frac{n}{3}$

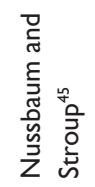




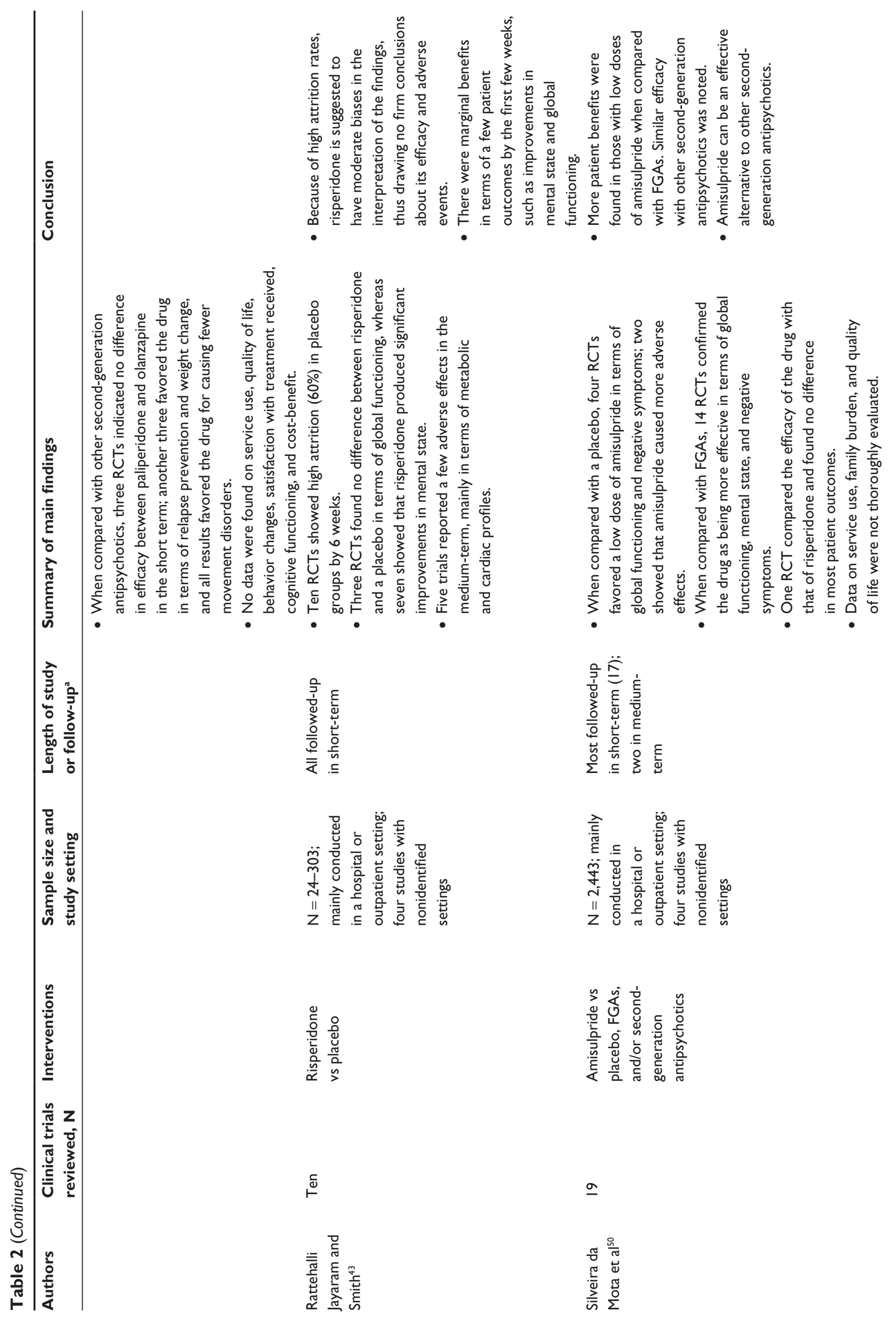



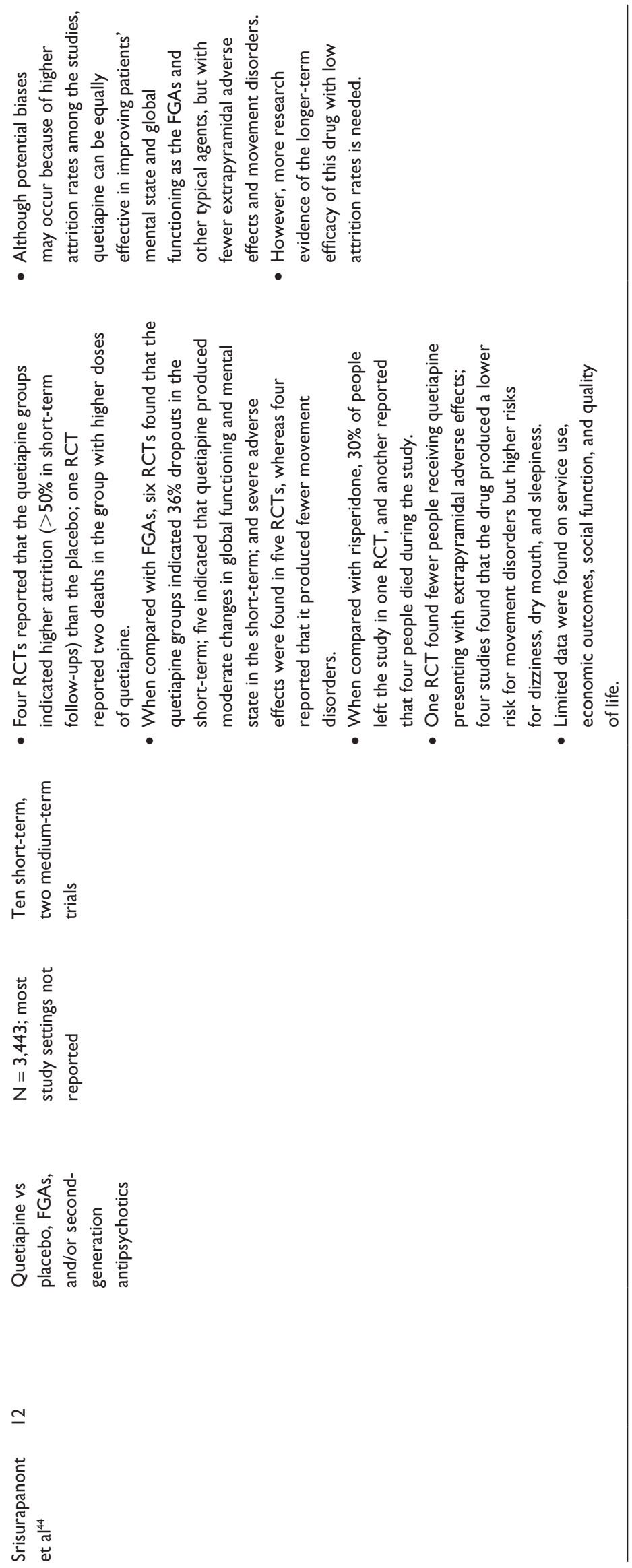
decrease relapse in both the short-term ( $<3$ months; $\mathrm{n}=310$; risk ratio, 0.59 [95\% confidence interval, 0.45-0.77]) and medium-term (3-6 months; $n=310$; risk ratio, $0.66[95 \%$ confidence interval, 0.53-0.81]) when compared with placebo controls. ${ }^{48}$ Aripiprazole can also produce less attrition and better compliance with study protocol $(n=2,275$; risk ratio, 0.74 [95\% confidence interval, 0.59-0.93]), and lower risk for raised prolactin level than that expected from the placebo $(n=305$; risk ratio, 0.21 [95\% confidence interval, $0.11-0.37])$.

Apart from oral medication, inhaled loxapine is considered a well-tolerated and rapid acute treatment for agitation but needs further longer-term controlled trials to verify its efficacy. ${ }^{53}$ Studies on relatively new second-generation antipsychotics such as ziprasidone have shown that their efficacy on positive symptoms is much better than that of other second-generation antipsychotics, whereas ziprasidone and lurasidone are clinically valuable and suggested to be taken with food. ${ }^{34,54}$

Most of the reviews appear not only to be concerned with their clinical efficacy and tolerability but also to pay more attention to psychosocial functioning and cognitive performance in activities of daily living. Among few systematic reviews/meta-analyses of the effect of FGAs on cognition in schizophrenia, one meta-analysis by Mishara and Goldberg ${ }^{55}$ included 34 randomized, placebo-controlled trials and suggested that most FGAs can provide modest to moderate benefits (ie, effect sizes ranged from 0.13 to 0.29 ) in multiple cognitive domains, whereas motor function was affected negatively. Although most of the newest secondgeneration antipsychotics have shown similar treatment efficacy in improving mental state and general functioning, they have not yet shown significant differences or consistent effects on reducing negative symptoms or cognitive dysfunction. ${ }^{36,56-60}$ Although one review reported that social functioning was better for people with schizophrenia taking the newer second-generation antipsychotics, ${ }^{36}$ most of the controlled trials only evaluated their efficacy over 3-6 months, and very high attrition rates and limited longterm effects on cognitive functioning, quality of life, service use and satisfaction, and other psychosocial functioning and behaviors were noted. ${ }^{36,57-62}$ Therefore, it is difficult to draw conclusions with regard to these second-generation antipsychotics, both on most patient outcomes, particularly in the longer-term, or on their cost benefits. ${ }^{46,49,63}$ Nevertheless, it is noteworthy that a recent population-based cohort study in Finland with 11 years of follow-up indicated decreased rates of mortality with perphenazine when compared with the other FGAs and a few second-generation antipsychotics and that only the use of clozapine was associated with lower rates of overall mortality. ${ }^{64}$

In conclusion, FGAs and second-generation antipsychotics are found to be similar and robust in treatment efficacy among acute and sometimes chronic schizophrenia, particularly against positive and disorganization symptoms. ${ }^{65}$ Their efficacy varies according to the course or stage of the illness; people with first-episode schizophrenia can respond faster and better to antipsychotics than those at later stages of the illness. In contrast, neither is effective in reducing negative symptoms, and they can even worsen the negative symptoms associated with extrapyramidal adverse effects (eg, antipsychotic-induced dysphoria). ${ }^{66}$ The efficacy of FGAs and second-generation antipsychotics on cognitive and social functioning, as well as other longer-term effects such as mortality and quality of life, are inconsistent. However, individual antipsychotics have shown significant differential efficacy in particular illness conditions and related problems, as well as different adverse effects. All of them reveal their onset of action within a few days and achieve optimal antipsychotic effect over the course of several weeks. Although antipsychotics substantially decrease patients' relapse from schizophrenia, it is not possible to ensure medication or other treatment compliance; thus, longterm injectable antipsychotics (eg, oil-based fluphenazine decanoate) may be considered. In view of the significantly varied pharmacokinetics of and treatment responses to antipsychotics among people with schizophrenia, it is recommended not only to examine the overall efficacy within and across patient groups but also to consider the efficacy of each antipsychotic medication for each individual patient when it is prescribed. ${ }^{67,68}$

\section{Safety and tolerability of antipsychotics}

Antipsychotics, particularly FGAs, can have a wide range of undesirable and adverse effects on patients, mainly including neurological, metabolic, cardiovascular, hematological, endocrine, and genitourinary disturbances. In addition, they differ from one to another in the levels and nature of these adverse effects. Although a few had less-extreme adverse effects (eg, perphenazine and sulpiride), ${ }^{26,29}$ all of the reviews indicated that the profile of adverse events concerning these adverse effects found in most FGAs (eg, acute extrapyramidal symptoms and tardive dyskinesia) is substantial and of major concern, thus reducing patients' medication compliance and treatment efficacy. ${ }^{23,24,26-30,33}$ 
Nevertheless, most second-generation antipsychotics have comparatively fewer and lower levels of adverse effects such as movement disorder, increased prolactin, and cardiac and sedative problems, than FGAs. In contrast, there may be higher risks for dizziness, sedation, weight gain, substantial increases in serum prolactin, and tachycardia for individual second-generation antipsychotics. ${ }^{44-48,69}$ However, there has not been any systematic work or classification to categorize or distinguish the risks of these adverse effects between antipsychotics, particularly the second-generation antipsychotics. As these adverse effects may affect aspects of patients' lives and treatment adherence and satisfaction, more work on such classification of antipsychotics in terms of their types or levels of adverse effects should be considered.

Clozapine, the first second-generation antipsychotic, does not show any extrapyramidal effects or tardive dyskinesia, but other serious adverse effects such as agranulocytosis and metabolic syndrome have limited its utility. In contrast, Tiihonen et $\mathrm{al}^{64}$ reported that clozapine was associated with a significantly lower mortality rate than other antipsychotics and also concluded that a lower mortality rate could be associated with a longer-term use of antipsychotics. Although clozapine is expected to have higher risks of a few adverse effects, inducing increased mortality, the researchers explained it has been shown to demonstrate very positive effects on symptom reduction and treatment compliance. Studies on relatively new second-generation antipsychotics such as ziprasidone have shown that they had fewer adverse effects in terms of metabolic profile (eg, metabolic disturbance and weight gain) and cognitive functioning and that their effects on positive symptoms are much better than those of other second-generation antipsychotics. ${ }^{34,44}$ Lurasidone has also indicated a highly favorable metabolic profile but is still not free from adverse events such as akathisia and Parkinson's syndrome. ${ }^{35}$

A large, 25-year cohort study measuring the mortality of 370 people with schizophrenia in Southampton, United Kingdom, reported that the cohort had an all-cause standardized mortality ratio of 289 (95\% confidential interval, 247-337), indicating small and nonsignificant changes between 1981 and 2006 but falling sharply from 376 (1981-1986) to 264 (1986-1991) in the first 10 years..$^{70}$ This considerable reduction of mortality rate in the 1980 s was mainly a result of a significant fall in unnatural deaths over the period (ie, the mortality ratio of suicide decreased from 6,110 in 1981-1986 to 0 in 1986-1991). In addition, the findings of the study support previous findings that people with schizophrenia have a mortality between two and three times that of the general populations, ${ }^{74}$ as well as raise concern about the cardiovascular mortality of schizophrenia, which has significantly increased during the past 25 years. ${ }^{80}$ Nevertheless, the effects of clozapine and other secondgeneration antipsychotics on mortality and treatment compliance among patients with schizophrenia reveal the difficulties in linking medium- or long-term patient outcomes with short-term drug effects; that is, whether symptom reduction can be mainly explained by the efficacy of antipsychotic use. It is therefore recommended that more longitudinal research be conducted with longer-term follow-up on predictors or mediators of patient outcomes in schizophrenia in relation to antipsychotic use.

\section{Patterns in medication use: mono- and polypharmacy}

Treatment of people with schizophrenia who are resistant to treatment and have persistent cognitive and negative symptoms remains a challenge to most clinicians. Many controlled trials of antipsychotics and their combined use with other psychotropic drugs (eg, acetylcholinesterase inhibitors, glutamatergic agents, antidepressants, benzodiazepines, and anticonvulsants) have been carried out in people with treatment-resistant and chronic schizophrenia, particularly on the means for improvement of negative symptoms, quality of life, and social function. However, very limited and weak evidence has been shown to confirm whether a particular antipsychotic medication or any of the combination strategies used could be efficacious in main patient outcomes and/or superior to the others in the treatment of schizophrenia, ${ }^{71-76}$ and none can be considered a robust treatment or prevention prescription for schizophrenia care. ${ }^{77-84}$ Nevertheless, psychosocial interventions, together with pharmacological treatment, are recommended to be the most effective strategies in the treatment and rehabilitation of people with schizophrenia. ${ }^{85}$

Despite such inconclusive and weak evidence on pharmacological agents to control negative symptoms or treatment-resistant cases, some combinations of medication use have indicated modest to satisfactory benefits in targeting specific psychotic symptoms. ${ }^{71,86-88}$ For instance, anticonvulsants such as valproic acid and carbamazepine are found to be useful as adjuncts to antipsychotics in treating aggression and impulsivity in schizophrenia, ${ }^{75,76}$ and adjunctive antidepressants can be useful in treating depression and anxiety symptoms and in reducing craving in comorbid substance use..$^{83,84,89}$ Interestingly, a double-blinded, multicenter randomized placebo-controlled trial on the effects 
of a Warm-Supplementing Kidney Yang capsule containing 13 traditional Chinese herbs indicated that the capsule had demonstrated significant improvements in quality of life and social function, as well as in depression symptoms, in 200 patients with schizophrenia at a 4-week follow-up. ${ }^{90}$

Depot injections have also been used extensively for controlling treatment noncompliance and long-term maintenance therapy, thus reducing the risk of relapse..$^{91-93}$ Reviews on second-generation antipsychotic or FGA depots (eg, bromperidol decanoate, haloperidol depot, risperidone depot, and fluphenazine decanoate) versus oral antipsychotic drugs and placebo indicated that patients with FGA depots had few relapses and fewer oral medications, even though the difference did not reach statistical significance. ${ }^{94-96}$ Together with similar levels of adverse effects found in depot medications, it was also difficult to conclude that a particular depot was no better than any other depot or oral medication. ${ }^{96}$ Despite showing similar clinical efficacy between oral and depot medications, depot injections can avoid frequent regular administration of and nonadherence to oral medication, rendering them more desirable for maintenance or compliance therapy.

\section{Pharmacological treatment used in different developmental stages of life}

During the last decade, there have been an increasing number of randomized controlled trials of the efficacy and safety of the FGAs and secondary-generation antipsychotics in children and adolescents with schizophrenia, involving double-blind, placebo-controlled, or open-labeled design and short- to medium-term follow-up (ie, 4-8 weeks). ${ }^{97-103}$ Those aged 12-17 years were usually included in the controlled trials, and a wide variety of second-generation antipsychotics such as quetapine, ${ }^{97}$ risperidone, ${ }^{98}$ paliperidone, ${ }^{99}$ and olanzapine ${ }^{100}$ were tested. A few main patient outcomes were commonly used, including global functioning, symptom severity, and quality-of-life assessment; however, few of the studies involved any long-term follow-up (ie, $>8$ weeks). ${ }^{97-103}$ In addition, a few types of treatment-emergent adverse events specifically for the second-generation antipsychotic used were observed (eg, metabolic and endocrine abnormalities for olanzapine and somnolence, agitation and electrocardiogram (ECG) and ophthalmic abnormalities for quetiapine). Similar to other age groups, most of the antipsychotics have had positive benefits for adolescents on reducing psychotic symptoms and global functioning, and the treatment was well-tolerated with acceptable levels of adverse events in low and medium dosages. None of the FGAs or second-generation antipsychotics has shown its superiority over the others, and the benefits of polypharmacy to any psychotic symptoms and comorbidities such as mood disorders for adolescents are also inconclusive. ${ }^{102,103}$ Nonetheless, it is suggested that antipsychotics are generally better tolerated and more effective in early psychosis.

Interestingly, a case study on a 17-year-old patient with intractable catatonic schizophrenia showed moderate effects in the resumption of spontaneous movement as a result of ECT as an adjunct to clozapine treatment. ${ }^{104}$ The researchers suggested that appropriate combinations of antipsychotic medication and other treatment modalities could also be considered in young patients, although it would be unusual.

It is estimated globally that about $23 \%$ of hospitalized patients with schizophrenia are older than 40 years and that more than $0.1 \%$ of elderly people have a diagnosis of lateonset schizophrenia. ${ }^{105}$ Very few studies have been done on those aged more than 65 years, and thus there are inadequate data and evidence to support any guidelines for treatment of late-onset schizophrenia or to serve these older patients' quality of life, functioning, and service use. ${ }^{105,106}$

\section{ECT and other treatments}

ECT, in which clonic seizure is electrically induced in anesthetized patients for therapeutic effects such as improved mood and volition, was commonly used in the $1930 \mathrm{~s}-1970$ s. One of the major patient groups for this treatment comprised those with schizophrenia or schizoaffective disorder. Although recent research findings are limited, ECT is considered an alternative treatment for those with unfavorable responses to antipsychotics alone after receiving different courses of medical or psychological treatment, and/or those with very strong suicidality and catatonic features. ${ }^{107,108}$ It is an effective adjunct to clozapine in treating refractory schizophrenia. ${ }^{104}$ There is certainly no strong or conclusive evidence to suggest that ECT alone or as an adjunct to antipsychotics is superior to antipsychotics alone or to any combination of different treatment modalities for schizophrenia. In addition, ECT may cause short-term, or occasionally long-term, memory impairment and leaves many unanswered questions about its role and mechanisms in the treatment of schizophrenia. ${ }^{108}$ Similarly, transcranial magnetic stimulation (a procedure that uses magnetic fields to stimulate the depolarization or hyperpolarization of the neuron cells in the cortical regions of the brain) has shown preliminary positive evidence in treating refractory negative symptoms and auditory hallucinations. ${ }^{109,110}$ 
It is also believed that Chinese herbal medicine produces progressive positive changes in physiological and mental state and fewer adverse effects when compared with Western medicine. The adverse effects of antipsychoticsinduced psycho- and physiopathological changes (eg, dysfunctions of the body organs and sleep-wake cycle) in the body can be treated with such herbal medicine, which is considered to promote the Yin-Yang balance and maintain a homeostatic environment of the internal bodily condition. ${ }^{111}$ Electroacupuncture for schizophrenia sufferers with auditory hallucination who were partially or fully nonresponsive to risperidone monotherapy was studied with a small-sized sample. The results showed that there was no significance difference between the two treatment modalities in terms of adverse effects, whereas electroacupuncture could induce a satisfactory improvement in auditory hallucination and a few other positive symptoms. ${ }^{112}$ Nevertheless, no conclusions were drawn on the potential efficacy of traditional Chinese medicine in treating schizophrenia, because of the very limited empirical evidence on this topic.

\section{Approaches to treatment for schizophrenia from prodromal to later stages of illness}

Various pharmacological treatments and psychosocial interventions for people with schizophrenia have been developed and evaluated over the last four decades. Although these innovative treatments and interventions have aroused much attention and accelerated deinstitutionalization, moderately low improvements in recovery, community-based rehabilitation, and quality of life among people with schizophrenia have been the result. The modest nature of these improvements may be because of the limited accessibility and availability of different alternatives or combined treatments and/or very advanced pathological and severe symptoms of patients when they present to and seek treatments from the mental healthcare system. ${ }^{66}$ More important, current treatments demonstrate that fairly positive patient outcomes in schizophrenia can be explained by the fact that most treatment plans do not vary across the course of the illness, even though different psychopathological processes are closely linked with different stages of schizophrenia. The three main stages of schizophrenia can include the premorbid and prodromal stage, the first onset or episode of acute illness, and the later stages of ongoing management, rehabilitation, and recovery.

To better understand the common treatment modalities, their main purposes, and their levels of effectiveness and reproducibility, a summary of current approaches to treatments for schizophrenia specific to the three stages of schizophrenia mentioned earlier is presented in Table 3. In the summary of the current body of knowledge about phasespecific treatment approaches (Table 3 ), it is essential to note that the mainstay treatments and management strategies of schizophrenia seem to have evolved at a slow pace and are highly reliant on antipsychotic agents as the basic treatment for all schizophrenia sufferers. The effectiveness and/or costbenefit analysis of most psychosocial interventions used, as well as their superiority and therapeutic components, are somewhat inconsistent and inconclusive.

Throughout the course of schizophrenia, more than 70 types of antipsychotic agents classified into first- and secondgeneration groups can be useful for symptom management. Nearly all antipsychotics share similar properties to block the dopamine D-2 receptor in terms of different potencies relating to their affinity for the receptor. ${ }^{19}$ They show no major differences in clinical efficacy for the overall schizophrenia group in meta-analyses of recent placebo-controlled studies. ${ }^{40,66,113}$ Although antipsychotics are found to significantly reduce a wide range of psychotic symptoms, and thus relapses, their effects on psychosocial functioning, cognitive and vocational skills, and longer-term community living skills in schizophrenia are vague and inadequately studied. ${ }^{114,115}$ It is also essential to point out that this similar overall efficacy reported in schizophrenia is not equal to and does not signify the same desirability or adverse effects, safety, tolerance, and/or other clinical responses in each individual patient.

Nevertheless, new pharmacological treatments for schizophrenia have been merging as a result of better understanding of its etiology and pathophysiology and the specific targeting of individual symptom domains. ${ }^{114}$ For instance, N-methylD-aspartate glutamate receptor agonists and glycine site agonists have been used in combination with antipsychotics, or the activating agents of the metabotropic glutamate $2 / 3$ receptors, and can be successful in reducing negative symptoms. ${ }^{115}$ Alpha 7 nicotinic receptor agonists, dopamine 1 receptor agonists, and modulators of glutamatergic aminomethylphosphonic acid (AMPA) receptors have been found to be useful in reducing cognitive impairments in schizophrenia. ${ }^{116}$ Therefore, different pharmacological treatment plans can be designed to target different pathophysiological processes relevant to different stages of schizophrenia.

For the premorbid phase (Table 3), most people with psychotic features experience a lengthy prodromal period of nonspecific symptoms and slowly progressive functional impairments before the full emergence of the diagnostic 


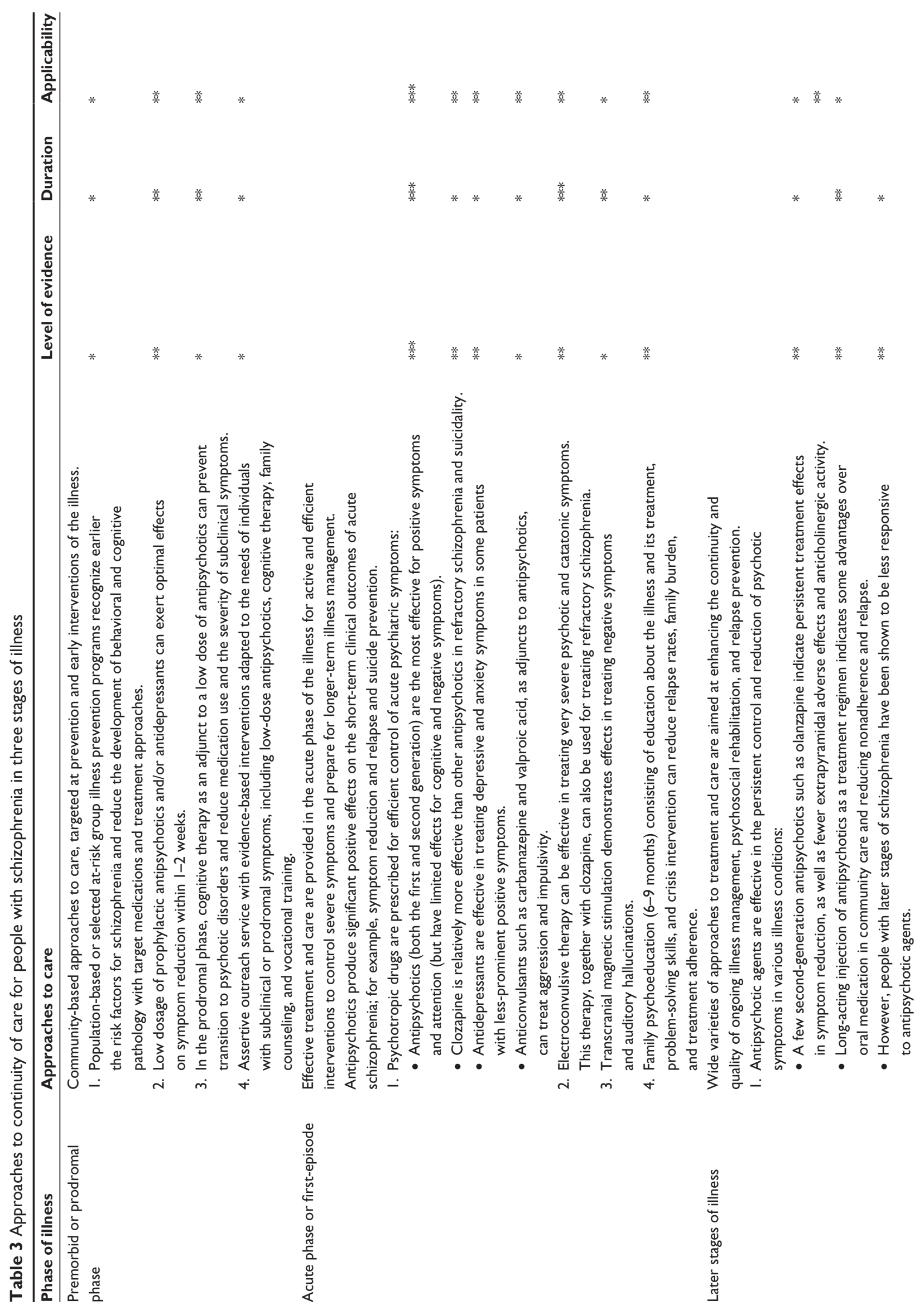




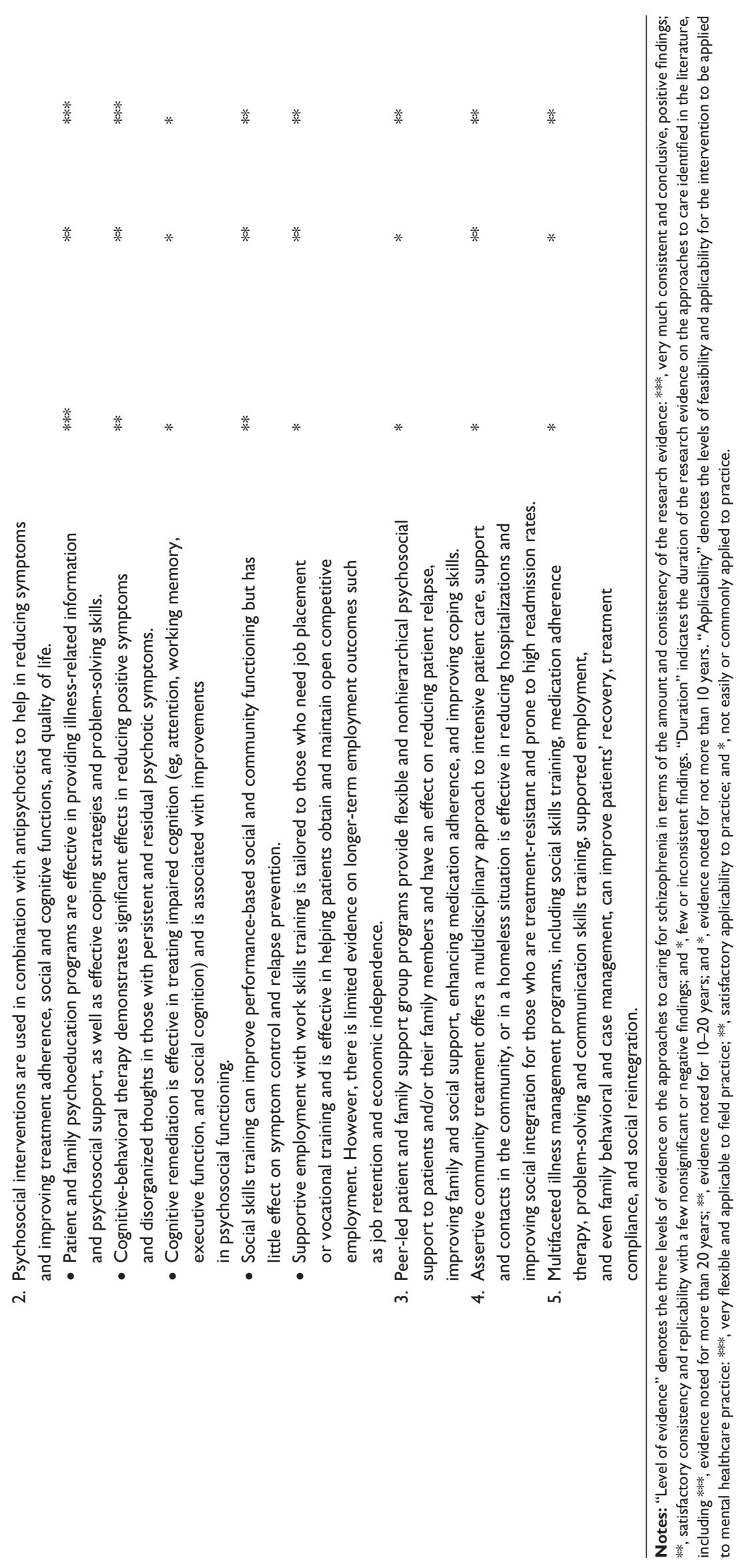


psychotic symptoms. The development of higher levels of dysfunction and disability during the prodromal period creates major inhibitory factors influencing recovery, thus providing very strong rationale for premorbid assessment and interventions. To promote accurate and valid assessment of high-risk individuals or groups, specific scales are being developed, such as the Bonn Scale for the Assessment of Basic Symptoms and the Comprehensive Assessment of At-Risk Mental State, as well as the Scale of Prodromal Symptoms. ${ }^{117,118}$ Without any of the strategies currently used, specific population-based prevention and assessment efforts should be made, targeting high-risk groups with mild early psychotic symptoms. Most important, identification of risk factors and symptomatic indicators is critical for accurately selecting at-risk persons and matching them to the most appropriate preventive treatment. As suggested by Birchwood, Todd, and Jackson's hypothesis of critical periods of onset and early intervention of psychosis, ${ }^{119}$ therapeutic interventions such as cognitive--behavioral therapy and assertive outreach services are most effective if they are offered at the earliest possible moment during the most vulnerable periods of illness onset. ${ }^{120,121}$ Research evidence suggesting that these cognitive and behavioral interventions can help people in the prodromal stage of schizophrenia is emerging, but is as yet inconclusive. ${ }^{122}$

In acute-episode or first-onset schizophrenia, the use of different antipsychotic agents is found to be crucial and effective in symptom reduction, especially for positive symptoms and attention. Second-generation (atypical) antipsychotics showing less risk for extrapyramidal adverse effects and tardive dyskinesia can be considered as the first-line treatment for acute psychosis. The second-generation antipsychotic clozapine is more effective in treating refractory schizophrenia and suicidality. ${ }^{123}$ Other psychotropic drugs such as antidepressants and anticonvulsants can be used as an adjunct to antipsychotics to control specific psychiatric symptoms such as depression, anxiety, aggression, and impulsivity. Physical treatments, especially ECT, are found effective in controlling a few treatment-resistive symptoms such as catatonic state, strongly depressive and suicidal ideation, and some negative symptoms. ${ }^{107}$ Repetitive transcranial magnetic stimulation studies have demonstrated some promise in the treatment of schizophrenia, particularly for those with treatment-resistant auditory hallucinations and severe mood problems. ${ }^{124}$ Family psychoeducation (6-9 months) can reduce relapse rates, family burden, and treatment adherence. ${ }^{7}$

For ongoing management and later-stage schizophrenia, a variety of psychosocial interventions are found useful in reducing patients' relapses and rehospitalizations, enhancing their functioning and medication adherence, and facilitating their rehabilitation and recovery. As indicated in Table 3, the more conclusive and consistent therapeutic interventions with moderate to large effect sizes in symptom control, relapse prevention, and levels of psychosocial functioning included patient and/or family psychoeducation programs, ${ }^{125}$ cognitive-behavioral therapy, ${ }^{126}$ and an integrated program with antipsychotics and different approaches to psychosocial care. ${ }^{127,128}$ Although small effect sizes to relapse prevention were found, a few commonly used approaches to psychosocial intervention for schizophrenia show increasingly consistent effects on specific patient outcomes, such as patients' social and community functioning being improved by social and vocational skills and shortterm competitive employment being enhanced by supported employment with work skills training. ${ }^{65,129}$

Similar to Amsterdam's first-aid service in the 1970s, crisis intervention models for people with schizophrenia and other serious mental illnesses have at times emerged, aimed at treating psychiatric crises in the community and reducing relapses and/or the number of hospitalizations. ${ }^{129}$ Multidisciplinary, around-the-clock crisis intervention services advocate prompt detection of symptom exacerbation and immediate intensive treatments as needed (eg, psychotropic agents, individual and family counseling, psychological therapies, and practical assistance in activities of daily living) in both community and home settings. Programs in Australia and the United States, such as mobile crisis teams, crisis units in hospitals, crisis day treatment centers, and crisis residential programs, have been integrated into routine mental healthcare services. ${ }^{64,130}$ Nevertheless, recent clinical trials suggested that about half of the crisis intervention groups indicated nonsignificant effects on improvements in mental state or reducing hospitalization during the treatment period, as well as lacking evidence of their long-term benefits in terms of patient outcomes. ${ }^{131}$ In addition, recent research has also evaluated the effectiveness of multifaceted illness management programs consisting of a wide variety of biological/ physical, psychological, and social interventions and suggested these programs might efficiently and effectively improve patient recovery and social reintegration. ${ }^{65,127,131}$

\section{Conclusion}

Antipsychotics (first- and/or second-generation antipsychotics) are shown to be effective in reducing overall psychotic symptoms and relapse in patients with schizophrenia. It is therefore recommended in most of the literature as first-line 
treatment for people with schizophrenia, at least in the short-term or at the acute stage of illness. However, the use of antipsychotics alone as the main treatment modality may be limited not only by their inability to tackle the frequently occurring negative symptoms and cognitive impairments but also by producing a wide variety of adverse effects in the internal body or organ functioning. The FGAs and secondgeneration antipsychotics are two distinct classes of antipsychotics with quite different potency and adverse effects, but these two classes do not have any definitive categorization between them in terms of efficacy, safety, and tolerability or in their clinical outcomes. However, because of the varied pharmacokinetics and patients' treatment responsiveness across different agents, the medication regimen should be determined on an individual basis to ensure optimal effect in their long-term use. Other medical and psychological treatments should be considered as an adjunct to antipsychotic agents. However, many of these alternative treatments are not strongly evidenced or conclusive in producing specific therapeutic effects in treating schizophrenia. More controlled trials are recommended to enhance understanding about their efficacy as a monotherapy or in combined use with antipsychotics, other medication, and/or psychosocial interventions.

Many patients with schizophrenia often have unresolved life events and psychological distress, as well as illnessrelated or drug-induced problems, which significantly affect their normalcy of daily life. In the last few decades, various models of psychosocial intervention have been developed and implemented as an adjunct to the pharmacological or other medical treatments at different stages of schizophrenia. The main purpose of these approaches to treatment is to provide these patients (and their family members) with adequate knowledge of and skills in this illness and its treatment and care, emotional support, problem-solving and coping skills, and/or enhancing cognitive and functional recovery. The current models commonly used for schizophrenia care include cognitive-behavioral therapy, psychoeducation, family intervention, social skills training, and cognitive remediation therapy. These psychosocial interventions and their comparative efficacy in treating people with schizophrenia will be discussed in another article. Recent systematic reviews on psychosocial interventions for schizophrenia have indicated significant positive medium-term (up to 18 months) effects of a few approaches (eg, psychoeducation and cognitive-behavioral therapy) integrated or embedded into routine care (and medication use) in people with acute or chronic schizophrenia. To overcome the shortcomings of antipsychotics in the treatment of schizophrenia, clinical guidelines and standards of practice have recommended that a combination of treatment methods or modalities be adopted to meet the complex psychiatric and other health needs of people with schizophrenia. We are assured of and also highly recommend more research in the clinical efficacy of different existing and new models of psychosocial interventions, together with antipsychotics or other psychotropic drugs, to ascertain a treatment approach for people with schizophrenia with the highest possible levels of efficacy, safety, and acceptability.

\section{Disclosure}

The authors report no conflicts of interest in this work.

\section{References}

1. American Psychiatric Association. Diagnostic and Statistical Manual of Mental Disorders. 4th ed. Washington, DC: American Psychiatric Association; 1994.

2. Dominguez Mde G, Viechtbauer W, Simons CJ, van Os J, Krabbendam L. Are psychotic psychopathology and neurocognition orthogonal? A systematic review of their associations. Psychol Bull. 2009;135(1):157-171.

3. Jablensky A. Prevalence and incidence of schizophrenia spectrum disorders: implications for prevention. Aust N Z J Psychiatry. 2000; 34 Suppl:S26-S34; discussion S35-S38.

4. Saha S, Chant D, McGrath J. A systematic review of mortality in schizophrenia: is the differential mortality gap worsening over time? Arch Gen Psychiatry. 2007;64(10):1123-1131.

5. van Os J, Linscott RJ, Myin-Germeys I, Delespaul P, Krabbendam L. A systematic review and meta-analysis of the psychosis continuum: evidence for a psychosis proneness-persistence-impairment model of psychotic disorder. Psychol Med. 2009;39(2):179-195.

6. National Institute for Health and Clinical Excellence. Schizophrenia. Core Interventions in the Treatment and Management of Schizophrenia in Primary and Secondary Care. National Clinical Practice Guideline 82. London: National Institute for Clinical Excellence; 2009.

7. Bilder RM. Neurocognitive impairment in schizophrenia and how it affects treatment options. Can J Psychiatry. 1997;42(3):255-264.

8. Bustillo J, Lauriello J, Horan W, Keith S. The psychosocial treatment of schizophrenia: an update. Am J Psychiatry. 2001;158(2):163-175.

9. Carpenter WT Jr, Heinrichs DW, Wagman AM. Deficit and nondeficit forms of schizophrenia: the concept. Am J Psychiatry. 1988;145(5): 578-583.

10. Hogarty GE, Anderson CM, Reiss DJ, et al. Family psychoeducation, social skills training, and maintenance chemotherapy in the aftercare treatment of schizophrenia. I. One-year effects of a controlled study on relapse and expressed emotion. Arch Gen Psychiatry. 1986;43(7): 633-642.

11. Patterson TL, Leeuwenkamp OR. Adjunctive psychosocial therapies for the treatment of schizophrenia. Schizophr Res. 2008;100(1-3): $108-119$.

12. Pfammatter M, Junghan UM, Brenner HD. Efficacy of psychological therapy in schizophrenia: conclusions from meta-analyses. Schizophr Bull. 2006;32 Suppl 1:S64-S80.

13. Rector NA, Beck AT. Cognitive behavioral therapy for schizophrenia: an empirical review. J Nerv Ment Dis. 2001;189(5):278-287.

14. Tandon R, Targum SD, Nasrallah HA, Ross R; Treatment Effectiveness in Schizophrenia Consortium. Strategies for maximizing clinical effectiveness in the treatment of schizophrenia. $J$ Psychiatr Pract. 2006;12(6):348-363. 
15. Pharoah F, Mari J, Rathbone J, Wong W. Family intervention for schizophrenia. Cochrane Database Syst Rev. 2010;(12):CD000088.

16. Kern RS, Glynn SM, Horan WP, Marder SR. Psychosocial treatments to promote functional recovery in schizophrenia. Schizophr Bull. 2009;35(2):347-361.

17. Jeppesen P, Petersen L, Thorup A, et al. Integrated treatment of firstepisode psychosis: effect of treatment on family burden: OPUS trial. Br J Psychiatry Suppl. 2005;48:s85-s90.

18. Buchanan RW, Kreyenbuhl J, Kelly DL, et al; Schizophrenia Patient Outcomes Research Team (PORT). The 2009 schizophrenia PORT psychopharmacological treatment recommendations and summary statements. Schizophr Bull. 2010;36(1):71-93.

19. Kapur S, Remington G. Dopamine D(2) receptors and their role in atypical antipsychotic action: still necessary and may even be sufficient. Biol Psychiatry. 1 2001;50(11):873-883.

20. World Health Organization. WHO Model List of Essential Medicines. 17th ed. Available from: http://www.who.int/medicines/publications/ essentialmedicines/en/index.html. Accessed June 18, 2013.

21. Adams CE, Awad G, Rathbone J, Thornley B. Chlorpromazine versus placebo for schizophrenia. Cochrane Database Syst Rev. 2012;(6):CD000284.

22. Liu X, De Haan S. Chlorpromazine dose for people with schizophrenia. Cochrane Database Syst Rev. 2009;(2):CD007778.

23. Marques LDO, Soares B, Silva de Lima M. Trifluoperazine for schizophrenia. Cochrane Database Syst Rev. 2004(1):CD003545.

24. Fenton M, Rathbone J, Reilly J. Thioridazine for schizophrenia. Cochrane Database Syst Rev. 2007(3):CD001944.

25. Rathbone J, McMonagle T. Pimozide for schizophrenia or related psychoses. Cochrane Database Syst Rev. 2001;(5):CD001949.

26. Hartung B, Wada M, Laux G, Leucht S. Perphenazine for schizophrenia. Cochrane Database Syst Rev. 2010;(5):CD003443.

27. Matar HE, Almerie MQ, Sampson S. Fluphenazine (oral) versus placebo for schizophrenia. Cochrane Database Syst Rev. 2013;(7):CD006352.

28. Leucht S, Hartung B. Perazine for schizophrenia. Cochrane Database Syst Rev. 2006;(2):CD002832.

29. Soares BGO, Fenton M, Chue P. Sulpiride for schizophrenia. Cochrane Database Syst Rev. 1999;(1):CD001162.

30. Kumar A, Strech D. Zuclopenthixol dihydrochloride for schizophrenia. Cochrane Database Syst Rev. 2005;(4):CD005474.

31. Irving $\mathrm{CB}$, Adams $\mathrm{CE}$, Lawrie $\mathrm{S}$. Haloperidol versus placebo for schizophrenia. Cochrane Database Syst Rev. 2006;(4):CD003082.

32. Leucht C, Kitzmantel M, Kane J, Leucht S, Chua WLLC. Haloperidol versus chlorpromazine for schizophrenia. Cochrane Database Syst Rev. 2008;(1):CD004278.

33. Soares BGO, Silva de Lima M. Penfluridol for schizophrenia. Cochrane Database Syst Rev. 2006(2):CD002923.

34. Alptekin K, Hafez J, Brook S, et al. Efficacy and tolerability of switching to ziprasidone from olanzapine, risperidone or haloperidol: an international, multicenter study. Int Clin Psychopharmacol. 2009;24(5): 229-238.

35. Citrome L. Lurasidone for schizophrenia: a review of the efficacy and safety profile for this newly approved second-generation antipsychotic. Int J Clin Pract. 2011;65(2):189-210.

36. Tuunainen A, Wahlbeck K. Newer atypical antipsychotic medication versus clozapine for schizophrenia. Cochrane Database Syst Rev. 2000;(2):CD000966.

37. Leucht S, Corves C, Arbter D, Engel RR, Li C, Davis JM. Secondgeneration versus first-generation antipsychotic drugs for schizophrenia: a meta-analysis. Lancet. 3 2009;373(9657):31-41.

38. Gabriel A. Risperidone, quetiapine, and olanzapine adjunctive treatments in major depression with psychotic features: a comparative study. Neuropsychiatr Dis Treat. 2019;485-492.

39. Davis JM, Chen N, Glick ID. A meta-analysis of the efficacy of secondgeneration antipsychotics. Arch Gen Psychiatry. 2003;60(6):553-564.

40. Leucht S, Wahlbeck K, Hamann J, Kissling W. New generation antipsychotics versus low-potency conventional antipsychotics: a systematic review and meta-analysis. Lancet. 2003;361(9369):1581-1589.
41. Kerwin RW. The new atypical antipsychotics. A lack of extrapyramidal side-effects and new routes in schizophrenia research. Br J Psychiatry. 1994;164(2):141-148.

42. Silverstone T, Turner P. Drug Treatment in Psychiatry. 5th ed. London: Routledge; 1995.

43. Rattehalli RD, Jayaram MB, Smith M. Risperidone versus placebo for schizophrenia. Cochrane Database Syst Rev. 2010;(1):CD006918.

44. Srisurapanont M, Maneeton B, Maneeton N, Lankappa S, Gandhi R. Quetiapine for schizophrenia. Cochrane Database Syst Rev. 2004;(2): CD000967.

45. Nussbaum AM, Stroup TS. Oral paliperidone for schizophrenia. Cochrane Database Syst Rev. 2008;(2):CD006369.

46. Duggan L, Fenton M, Rathbone J, Dardennes R, El-Dosoky A, Indran S. Olanzapine for schizophrenia. Cochrane Database Syst Rev. 2005;(2): CD001359.

47. Chakrabarti A, Bagnall AM, Chue P, et al. Loxapine for schizophrenia. Cochrane Database Syst Rev. 2007;(4):CD001943.

48. Belgamwar RB, El-Sayeh HGG. Aripiprazole versus placebo for schizophrenia. Cochrane Database Syst Rev. 2011;(8):CD006622.

49. El-Sayeh HG, Morganti C. Aripiprazole for schizophrenia. Cochrane Database Syst Rev. 2006;(2):CD004578.

50. Silveira da Mota Neto JI, Soares BGO, Silva de Lima M. Amisulpride for schizophrenia. Cochrane Database Syst Rev. 2002;(2):CD001357.

51. Salimi K, Jarskog LF, Lieberman JA. Antipsychotic drugs for firstepisode schizophrenia: a comparative review. CNS Drugs. 2009;23(10): 837-855.

52. Lieberman JA, Stroup TS, McEvoy JP, et al; Clinical Antipsychotic Trials of Intervention Effectiveness (CATIE) Investigators. Effectiveness of antipsychotic drugs in patients with chronic schizophrenia. $N$ Engl $J$ Med. 2005;353(12):1209-1223.

53. Lesem MD, Tran-Johnson TK, Riesenberg RA, et al. Rapid acute treatment of agitation in individuals with schizophrenia: multicentre, randomised, placebo-controlled study of inhaled loxapine. $\mathrm{Br} J$ Psychiatry. 2011;198(1):51-58.

54. Karayal ON, Glue P, Bachinsky M, et al. Switching from quetiapine to ziprasidone: a sixteen-week, open-label, multicenter study evaluating the effectiveness and safety of ziprasidone in outpatient subjects with schizophrenia or schizoaffective disorder. $J$ Psychiatr Pract. 2011;17(2):100-109.

55. Mishara AL, Goldberg TE. A meta-analysis and critical review of the effects of conventional neuroleptic treatment on cognition in schizophrenia: opening a closed book. Biol Psychiatry. 2004;55(10): 1013-1022.

56. Gilbody S, Bagnall AM, Duggan L, Tuunainen A. Risperidone versus other atypical antipsychotic medication for schizophrenia. Cochrane Database Syst Rev. 2000;(3):CD002306.

57. Subramanian S, Rummel-Kluge C, Hunger $\mathrm{H}$, et al. Zotepine versus other atypical antipsychotics for schizophrenia. Cochrane Database Syst Rev. 2010;(10):CD006628.

58. Komossa K, Rummel-Kluge C, Hunger H, et al. Sertindole versus other atypical antipsychotics for schizophrenia. Cochrane Database Syst Rev. 2009;(2):CD006752.

59. Komossa K, Rummel-Kluge C, Schwarz S, et al. Risperidone versus other atypical antipsychotics for schizophrenia. Cochrane Database Syst Rev. 2011;(1):CD006626.

60. Komossa K, Rummel-Kluge C, Hunger H, et al. Olanzapine versus other atypical antipsychotics for schizophrenia. Cochrane Database Syst Rev. 2010;(3):CD006654.

61. Asenjo Lobos C, Komossa K, Rummel-Kluge C, et al. Clozapine versus other atypical antipsychotics for schizophrenia. Cochrane Database Syst Rev. 2010;(11);CD006633.

62. Komossa K, Rummel-Kluge C, Schmid F, et al. Aripiprazole versus other atypical antipsychotics for schizophrenia. Cochrane Database Syst Rev. 2009;(4):CD006569.

63. Essali A, Al-Haj Haasan N, Li C, Rathbone J. Clozapine versus typical neuroleptic medication for schizophrenia. Cochrane Database Syst Rev. 2009;(1):CD000059. 
64. Tiihonen J, Lönnqvist J, Wahlbeck K, et al. 11-year follow-up of mortality in patients with schizophrenia: a population-based cohort study (FIN11 study). Lancet. 2009;374(9690):620-627.

65. Dixon L, Perkins D, Calmes C. Guideline Watch: Practice Guideline for the Treatment of Patients with Schizophrenia. Arlington, VA: American Psychiatric Association; 2009.

66. Tandon R, Nasrallah HA, Keshavan MS. Schizophrenia, "just the facts" 5 . Treatment and prevention. Past, present, and future. Schizophr Res. 2010;122(1-3):1-23.

67. Hamann J, Kissling W, Leucht S, Rummel-Kluge C. New generation antipsychotics for first episode schizophrenia. Cochrane Database Syst Rev. 2003;(4):CD004410.

68. Bola J, Kao D, Soydan H, Adams CE. Antipsychotic medication for early episode schizophrenia. Cochrane Database Syst Rev. 2011;(6): CD006374.

69. Lewis R, Bagnall AM, Leitner M. Sertindole for schizophrenia. Cochrane Database Syst Rev. 2005;(3):CD001715.

70. Brown S, Kim M, Mitchell C, Inskip H. Twenty-five year mortality of a community cohort with schizophrenia. Br J Psychiatry. 2010;196(2): $116-121$.

71. Singh J, Kour K, Jayaram MB. Acetylcholinesterase inhibitors for schizophrenia. Cochrane Database Syst Rev. 2012;(1):CD007967.

72. Shekhar A, Potter WZ, Lightfoot J, et al. Selective muscarinic receptor agonist xanomeline as a novel treatment approach for schizophrenia Am J Psychiatry. 2008;165(8):1033-1039.

73. Wang J, Omori IM, Fenton M, Soares BGO. Sulpiride augmentation for schizophrenia. Cochrane Database Syst Rev. 2010;(1):CD008125.

74. Buchanan RW, Javitt DC, Marder SR, et al. The Cognitive and Negative Symptoms in Schizophrenia Trial (CONSIST): the efficacy of glutamatergic agents for negative symptoms and cognitive impairments. Am J Psychiatry. 2007;164(10):1593-1602.

75. Schwarz C, Volz A, Li C, Leucht S. Valproate for schizophrenia Cochrane Database Syst Rev. 2008;(3):CD004028.

76. Leucht S, Kissling W, McGrath J, White P. Carbamazepine for schizophrenia. Cochrane Database Syst Rev. 2007;(3):CD001258.

77. Elias A, Kumar A. Testosterone for schizophrenia. Cochrane Database Syst Rev. 2007;(3):CD006197.

78. Irving CB, Mumby-Croft R, Joy LA. Polyunsaturated fatty acid supplementation for schizophrenia. Cochrane Database Syst Rev. 2006;(3);CD001257.

79. Leucht S, Kissling W, McGrath J. Lithium for schizophrenia. Cochrane Database Syst Rev. 2007;(3);CD003834.

80. Premkumar TS, Pick J. Lamotrigine for schizophrenia. Cochrane Database Syst Rev. 2006;(4):CD005962.

81. Tiihonen J, Wahlbeck K. Glutamatergic drugs for schizophrenia. Cochrane Database Syst Rev. 2006;(2):CD003730.

82. Dold M, Li C, Tardy M, Khorsand V, Gillies D, Leucht S. Benzodiazepines for schizophrenia. Cochrane Database Syst Rev. 2012;(11):CD006391.

83. Rummel-Kluge C, Kissling W, Leucht S. Antidepressants for the negative symptoms of schizophrenia. Cochrane Database Syst Rev. 2006;(3):CD005581.

84. Singh SP, Singh V, Kar N, Chan K. Efficacy of antidepressants in treating the negative symptoms of chronic schizophrenia: meta-analysis. Br J Psychiatry. 2010;197(3):174-179.

85. Swartz MS, Perkins DO, Stroup TS, et al; CATIE Investigators. Effects of antipsychotic medications on psychosocial functioning in patients with chronic schizophrenia: findings from the NIMH CATIE study. Am J Psychiatry. 2007;164(3):428-436.

86. Mico'U, Bruno A, Pandolfo G, et al. Duloxetine as adjunctive treatment to clozapine in patients with schizophrenia: a randomized, placebocontrolled trial. Int Clin Psychopharmacol. 2011;26(6):303-310.

87. Lerner V, Miodownik C, Gibel A, et al. Bexarotene as add-on to antipsychotic treatment in schizophrenia patients: a pilot open-label trial. Clin Neuropharmacol. 2008;31(1):25-33.

88. Leucht S, Pitschel-Walz G, Engel RR, Kissling W. Amisulpride, an unusual "atypical" antipsychotic: a meta-analysis of randomized controlled trials. Am J Psychiatry. 2002;159(2):180-190.
89. Zisook S, Shear MK, Irwin SA. Death, dying, and bereavement. In: Sadock BJ, Sadock VA, Ruiz P, editors. Kaplan and Sadock's Comprehensive Textbook of Psychiatry. 9th ed. Philadelphia, PA: Lippincott Williams \& Wilkins; 2009:2378-2407.

90. Chen ZH, Wang GH, Wang XP, et al. Effect of Warm-Supplementing Kidney Yang (WSKY) added to risperidone on quality of life in patients with schizophrenia: a randomized controlled trial. Clin Rehabil. 2009;23(11):963-972.

91. West JC, Wilk JE, Olfson M, et al. Patterns and quality of treatment for patients with schizophrenia in routine psychiatric practice. Psychiatr Serv. 2005;56(3):283-291.

92. Kane JM, Aguglia E, Altamura AC, et al. Guidelines for depot antipsychotic treatment in schizophrenia. European Neuropsychopharmacology Consensus Conference in Siena, Italy. Eur Neuropsychopharmacol. 1998;8(1):55-66.

93. David AS, Cutting JC. The Neuropsychology of Schizophrenia. East Sussex, UK: Lawrence Erlbaum Associates; 1994.

94. Purgato M, Adams CE. Bromperidol decanoate (depot) for schizophrenia. Cochrane Database Syst Rev. 2012;(11):CD001719.

95. Dinesh M, David A, Quraishi SN. Depot pipotiazine palmitate and undecylenate for schizophrenia. Cochrane Database Syst Rev. 2004;(3):CD001720.

96. David A, Quraishi SN, Rathbone J. Depot perphenazine decanoate and enanthate for schizophrenia. Cochrane Database Syst Rev. 2005;(3): CD001717.

97. Shaw JA, Lewis JE, Pascal S, et al. A study of quetiapine: efficacy and tolerability in psychotic adolescents. $J$ Child Adolesc Psychopharmacol. 2001;11(4):415-424.

98. Haas M, Eerdekens M, Kushner S, et al. Efficacy, safety and tolerability of two dosing regimens in adolescent schizophrenia: double-blind study. Br J Psychiatry. 2009;194(2):158-164.

99. Singh J, Robb A, Vijapurkar U, Nuamah I, Hough D. A randomized, double-blind study of paliperidone extended-release in treatment of acute schizophrenia in adolescents. Biol Psychiatry. 2011;70(12): 1179-1187.

100. Kryzhanovskaya L, Schulz SC, McDougle C, et al. Olanzapine versus placebo in adolescents with schizophrenia: a 6-week, randomized, double-blind, placebo-controlled trial. J Am Acad Child Adolesc Psychiatry. 2009;48(1):60-70.

101. Masi G, Liboni F. Management of schizophrenia in children and adolescents: focus on pharmacotherapy. Drugs. 2011;71(2):179-208.

102. Sikich L, Frazier JA, McClellan J, et al. Double-blind comparison of first- and second-generation antipsychotics in early-onset schizophrenia and schizo-affective disorder: findings from the treatment of early-onset schizophrenia spectrum disorders (TEOSS) study. Am J Psychiatry. 2008;165(11):1420-1431.

103. Findling RL, Robb A, Nyilas M, et al. A multiple-center, randomized, double-blind, placebo-controlled study of oral aripiprazole for treatment of adolescents with schizophrenia. Am J Psychiatry. 2008;165(11):1432-1441.

104. Consoli A, Boulicot V, Cornic F, Fossati P, Barbeau M, Cohen D. Moderate clinical improvement with maintenance ECT in a 17-yearold boy with intractable catatonic schizophrenia. Eur Child Adolesc Psychiatry. 2009;18(4):250-254.

105. Essali A, Ali G. Antipsychotic drug treatment for elderly people with late-onset schizophrenia. Cochrane Database Syst Rev. 2012;(2): CD004162.

106. Marriott R, Neil W, Waddingham S. Antipsychotic medication for elderly people with schizophrenia. Cochrane Database Syst Rev. 2006;(1):CD005580.

107. Tharyan P, Adams CE. Electroconvulsive therapy for schizophrenia. Cochrane Database Syst Rev. 2005;(2):CD000076.

108. Fitzgerald PB. The emerging use of brain stimulation treatments for psychiatric disorders. Aust N Z J Psychiatry. 2011;45(11):923-938.

109. Blumberger DM, Fitzgerald PB, Mulsant BH, Daskalakis ZJ. Repetitive transcranial magnetic stimulation for refractory symptoms in schizophrenia. Curr Opin Psychiatry. 2010;23(2):85-90. 
110. Freitas C, Fregni F, Pascual-Leone A. Meta-analysis of the effects of repetitive transcranial magnetic stimulation (rTMS) on negative and positive symptoms in schizophrenia. Schizophr Res. 2009;108(1-3): 11-24.

111. Rathbone J, Zhang L, Zhang M, Xia J, Liu X, Yang Y. Chinese herbal medicine for schizophrenia. Cochrane Database Syst Rev. 2005;(4): CD003444.

112. Jing Cheng, Gaohua Wang, Ling Xiao, Huiling Wang, Xiaoping Wang, Chengyan Li. Electro-acupuncture versus sham electro-acupuncture for auditory hallucinations in patients with schizophrenia: a randomized controlled trial. Clin Rehabil. 2009;23(7):579-588.

113. Correll CU, Rummel-Kluge C, Corves C, Kane JM, Leucht S. Antipsychotic combinations vs monotherapy in schizophrenia: a metaanalysis of randomized controlled trials. Schizophr Bull. 2009;35(2): 443-457.

114. Carpenter WT, Koenig JI. The evolution of drug development in schizophrenia: past issues and future opportunities. Neuropsychopharmacology. 2008;33(9):2061-2079.

115. Patil ST, Zhang L, Martenyi F, et al. Activation of $\mathrm{mGlu} 2 / 3$ receptors as a new approach to treat schizophrenia: a randomized Phase 2 clinical trial. Nat Med. 2007;13(9):1102-1107.

116. Harvey PD. Pharmacological cognitive enhancement in schizophrenia. Neuropsychol Rev. 2009;19(3):324-335.

117. Klosterkötter J, Hellmich M, Steinmeyer EM, Schultze-Lutter F. Diagnosing schizophrenia in the initial prodromal phase. Arch Gen Psychiatry. 2001;58(2):158-164.

118. Miller TJ, McGlashan TH, Woods SW, et al. Symptom assessment in schizophrenic prodromal states. Psychiatr Q. 1999;70(4):273-287.

119. Birchwood M, Todd P, Jackson C. Early intervention in psychosis. The critical period hypothesis. Br J Psychiatry Suppl. 1991;72(33): 53-59.

120. Morrison AP, French P, Walford L, et al. Cognitive therapy for the prevention of psychosis in people at ultra-high risk: randomised controlled trial. Br J Psychiatry. 2004;185:291-297.
121. Tempier R, Balbuena L, Garety P, Craig TJ. Does assertive community outreach improve social support? Results from the Lambeth Study of early-episode psychosis. Psychiatr Serv. 2012;63(3):216-222.

122. Marshall M, Rathbone J. Early intervention for psychosis. Cochrane Database Syst Rev. 2011;(6):CD004718.

123. Remington G, Agid O, Foussias G, Hahn M, Rao N, Sinyor M. Clozapine's role in the treatment of first-episode schizophrenia. Am J Psychiatry. 2013;170(2):146-151.

124. Poulet E, Haesebaert F, Saoud M, Suaud-Chagny MF, Brunelin J. Treatment of shizophrenic patients and rTMS. Psychiatr Danub. 2010;22 Suppl 1:S143-S146.

125. Rummel-Kluge C, Kissling W. Psychoeducation in schizophrenia: new developments and approaches in the field. Curr Opin Psychiatry. 2008;21(2):168-172.

126. Wykes T, Steel C, Everitt B, Tarrier N. Cognitive behavior therapy for schizophrenia: effect sizes, clinical models, and methodological rigor. Schizophr Bull. 2008;34(3):523-537.

127. Chien WT, Lee IY. The schizophrenia care management program for family caregivers of Chinese patients with schizophrenia. Psychiatr Serv. 2010;61(3):317-320.

128. Malla AK, Norman RM, Manchanda R, et al. Status of patients with first-episode psychosis after one year of phase-specific communityoriented treatment. Psychiatr Serv. 2002;53(4):458-463.

129. Weisman GK. Crisis intervention. In: Bellack AS, editor. A Clinical Guide for the Treatment of Schizophrenia. New York: Plenum Press; 1989:101-134.

130. Irving CB, Adams CE, Rice K. Crisis intervention for people with severe mental illnesses. Cochrane Database Syst Rev. 2006;(4): CD001087.

131. National Collaborating Centre for Mental Health. Clinical Guideline 1 - Schizophrenia: Core Intervention in the Treatment and Management of Schizophrenia in Primary and Secondary Care. London: National Institute for Clinical Excellence; 2002.
Neuropsychiatric Disease and Treatment

\section{Publish your work in this journal}

Neuropsychiatric Disease and Treatment is an international, peerreviewed journal of clinical therapeutics and pharmacology focusing on concise rapid reporting of clinical or pre-clinical studies on a range of neuropsychiatric and neurological disorders. This journal is indexed on PubMed Central, the 'PsycINFO' database and CAS.

\section{Dovepress}

The manuscript management system is completely online and includes a very quick and fair peer-review system, which is all easy to use. Visit http://www.dovepress.com/testimonials.php to read real quotes from published authors. 